Working Papers of The University of Vaasa,

Department of Mathematics and Statistics,

17

Testing for Cumulative Abnormal Returns in Event Studies with the Rank Test

Terhi Luoma and Seppo Pynnönen

Preprint, November 2010

University of Vaasa

Department of Mathematics and Statistics

P.O.Box 700, FI-95101 Vaasa, Finland

Preprints available at: http://lipas.uwasa.fi/julkaisu/ewp.html 


\title{
Testing for Cumulative Abnormal Returns in Event Studies with the Rank Test
}

\begin{abstract}
Campbell and Wasley (1993) extend Corrado (1989) event study rank test for testing cumulative abnormal returns (CARs) in terms of cumulated ranks. The ranks are dependent by construction, which introduces incremental bias into the standard error of the statistic in longer CARs. This paper corrects the bias, derives a new $t$-ratio, and derives asymptotic distributions for this and other rank tests with fixed time series length. Simulations with real returns show that the proposed rank test is well specified in testing CARs, is robust in many respects, and has competitive (empirical) power relative to the most popular parametric tests.
\end{abstract}

Keywords: Cumulated ranks; Standardized abnormal returns; Asymptotic distribution; Market efficiency;

JEL Classification: G14; C10; C15

\section{Introduction}

Due to their better power properties the standardized tests of Patell (1976) and Boehmer, Musumeci and Poulsen (BMP) (1991) have gained popularity over the conventional nonstandardized tests in testing event effects on mean security price performance. Harrington and Shrider (2007) found that in a short-horizon test focusing on mean abnormal returns 
should always use tests that are robust against cross-sectional variation in the true abnormal return [for discussion of true abnormal return, see Harrington and Shrider (2007)]. They found that BMP is a good candidate for a robust, parametric test in conventional event studies. ${ }^{1}$ Corrado (1989) [and Corrado and Zivney (1992)] introduced a nonparametric rank test based on standardized returns, which has proven to have very competitive and often superior power properties over the above mentioned standardized tests [e.g. Corrado (1989), Corrado and Zivney (1992), Campbell and Wasley (1993) and Kolari and Pynnönen (2010)]. Furthermore, the rank test of Corrado and Zivney (1992) based on the event period re-standardized returns has proven to be both robust against the event-induced volatility [Campbell and Wasley (1993)] and to cross-correlation due to event day clusterings [Kolari and Pynnönen (2010)].

Patell and BMP parametric tests apply straightforwardly for testing cumulative abnormal returns (CARs) over multiple day windows. ${ }^{2}$ By construction Corrado (1989) and Corrado and Zivney (1992) rank test applies for testing single event period returns. Testing for CARs with the same logic implies the need of defining multiple-day returns that match the number of days in the CARs [c.f. Corrado (1989, p. 395) and Campbell and Wasley (1993,

\footnotetext{
${ }^{1}$ We define conventional event studies as those focusing only on mean stock price effects. Other types of event studies include (for example) the examination of return variance effects [Beaver (1968) and Patell (1976)], trading volume [Beaver (1968) and Campbell and Wasley (1996)], accounting performance [Barber and Lyon (1997)] and earnings management procedures [Dechow, Sloan, and Sweeney (1995) and Kothari, Leone, and Wasley (2005)].

${ }^{2}$ With the correction suggested in Kolari and Pynnönen (2010), these tests are useful also in the case of clustered event days.
} 
footnote 4)]. In practice this is achieved by dividing the estimation period and event period into intervals matching the number of days in the CAR. Unfortunately, this procedure is not very practical for a number of reasons. Two major reasons are that the multiple-day approach does not necessarily lead to a unique testing procedure and that the abnormal return model should be re-estimated for each multiple-day CAR definition. In addition, for a fixed estimation period, as the number of days accumulated in a CAR increases, the number of multiple-day estimation period observations reduces quickly unpractically low and thus, would weaken the abnormal return model estimation [c.f. Kolari and Pynnönen (2010)].

Therefore, for example Campbell and Wasley (1993) use Corrado's rank test for testing cumulative abnormal returns by simply accumulating the respective ranks to form cumulative ranks. This is also the practice adopted in the Eventus ${ }^{\circledR}$ software (Cowan Research L.C., www.eventstudy.com). However, also this cumulative ranks procedure has some obvious shortcomings. Cowan (1992) and Kolari and Pynnönen (2010b) demonstrate that the procedure looses quickly power to detect an event effect in cumulative abnormal returns if the event effect is randomly assigned to a single event day within the event window for each stock. Kolari and Pynnönen (2010) resolve this undesirable feature by suggesting a procedure in which the cumulative abnormal returns are mapped to the same scale as the single day abnormal returns. This allows for using the rank test in a well defined manner for testing both single day abnormal returns as well as cumulative abnormal returns.

In spite of this undesirable property, we believe that the cumulated ranks procedure has great potential in certain instances. One central role of event study testing is in studies related 
to the market efficiency. Under the efficiency hypothesis new information should instantaneously, without delays, fully be reflected in stock prices. Event study is an indispensable empirical tool to investigate the possible leaks or delays in the information. Leaks or delays in information imply gradual dissipation of the value change due to the information. In such circumstances methods that best can trace tiny changes are most effective in revealing the related market inefficiencies. Of the existing non-parametric methods the cumulated ranks test can be expected to be a promising candidate in this respect because it monitors each return via the rank number separately around the event days. This separate monitoring can be an advantage over methods based on accumulated returns. Another advantage of the cumulated ranks test, in particular with respect to above referred multi-day alternative, is its simplicity and uniqueness. Finally, in short windows of two or three days, which are typically the used window lengths reported in event studies, the cumulative ranks testing procedure can be expected to do fine even if the event is randomly assigned in only one of the dates.

Thus, the cumulated ranks test certainly has its place as a testing procedure in event studies. Because of its particular potential is most likely in those of market efficiency cases referred above, we think that it is warranted to derive the related test statistic into a form in which it follows its (asymptotic) distribution as closely as possible. A particular feature of the ranks of the abnormal returns of different days is that they are dependent by construction. Although over short windows the dependence should be negligible, in longer windows the dependence accumulates and will bias the rejection rates of the simple CAR rank test. This paper corrects the bias, derives a new $t$-ratio, and shows that it is asymptotically $t$-distributed 
with $T-2$ degrees of freedom as the number of series increases and $T$, the length of the time series, is finite. The paper also derives the asymptotic distribution for the standard error corrected cumulated ranks test, which coincides the Corrado and Zivney (1992) statistic in a single event day testing. Simulation studies based on actual returns demonstrate the usefulness of the correction and compares the procedure test against some of the most popular parametric tests. The proposed new test statistic is shown to have several advantages over the existing tests. First, it avoids the under-rejection symptom of cumulated ranks test as the CAR-window (days over which the CAR is computed) increases. Second, it is robust to event-induced volatility. Third, it proves to have competitive and often superior (empirical) power properties compared to popular parametric tests.

The rest of the paper is organized as follows. Section 2 defines the main concepts needed in the subsequent sections and derives some distributional properties of the statistics. Section 3 presents the major existing rank statistics, introduces the new rank test, and derives the asymptotic distributions of the tests. Section 4 describes the simulation design and the results of the simulation are presented in Section 5. Section 6 concludes.

\section{Distribution Properties of Rank Test to be Developed}

Next we introduce some necessary notations and concepts. We assume that the autocorrelations of the stock returns are negligible and make the following assumption: 
Assumption 1 Stock returns $r_{i t}$ are weak white noise continuous random variables with

$$
\begin{aligned}
E\left[r_{i t}\right] & =\mu_{i} \text { for all } t \\
\operatorname{var}\left[r_{i t}\right] & =\sigma_{i}^{2} \text { for all } t \\
\operatorname{cov}\left[r_{i t}, r_{i s}\right] & =0 \text { for all } t \neq s,
\end{aligned}
$$

where $i$ refers to the $i^{\text {th }}$ stock and $t$ and $s$ are time indexes. Furthermore $i=1, \ldots, n$, $t=1, \ldots, T$ and $s=1, \ldots, T$.

Let $\mathrm{AR}_{i t}$ denote the abnormal return of security $i$ on day $t$, and let day $t=0$ indicate the event day. ${ }^{3}$ Days from $t=T_{0}+1$ to $t=T_{1}$ represent the estimation period days relative to the event day, and days from $t=T_{1}+1$ to $t=T_{2}$ represent event window days, again relative to the event day. The cumulative abnormal return (CAR) from day $\tau_{1}$ to $\tau_{2}$ with $T_{1}<\tau_{1} \leq \tau_{2} \leq T_{2}$, is defined as

$$
\operatorname{CAR}_{i}\left(\tau_{1}, \tau_{2}\right)=\sum_{t=\tau_{1}}^{\tau_{2}} \operatorname{AR}_{i t}
$$

and the time period from $\tau_{1}$ to $\tau_{2}$ is often called a CAR-window or a CAR-period.

Standardized abnormal returns are defined as

$$
\mathrm{SAR}_{i t}=\mathrm{AR}_{i t} / S\left(\mathrm{AR}_{i}\right)
$$

where

$$
S\left(\mathrm{AR}_{i}\right)=\sqrt{\frac{1}{T_{1}-T_{0}-1} \sum_{t=T_{0}+1}^{T_{1}} \mathrm{AR}_{i t}^{2}} .
$$

\footnotetext{
${ }^{3}$ Abnormal returns are operationalized in Section 4.
} 
Furthermore, for the purpose of accounting the possible event induced volatility the restandardized abnormal returns are defined in the manner of Boehmer, Musumeci and Poulsen (1991) [see also Corrado and Zivney (1992)] as

$$
\mathrm{SAR}_{i t}^{\prime}= \begin{cases}\mathrm{SAR}_{i t} / S_{S A R_{t}} & \tau_{1} \leq t \leq \tau_{2} \\ \mathrm{SAR}_{i t} & \text { otherwise }\end{cases}
$$

where

$$
S_{S A R_{t}}=\sqrt{\frac{1}{n-1} \sum_{i=1}^{n}\left(\mathrm{SAR}_{i t}-\overline{\mathrm{SAR}}_{t}\right)^{2}}
$$

is the cross-sectional standard deviation of $A R_{i t}^{\prime} \mathrm{s}, \overline{\mathrm{AR}}_{t}^{\prime}=\frac{1}{n} \sum_{i=1}^{n} \mathrm{AR}_{i t}^{\prime}$, and $n$ is the number of stocks in the portfolio. Furthermore, let $R_{i t}=\operatorname{rank}\left(\mathrm{SAR}_{i t}^{\prime}\right)$ denote the rank number of re-standardized abnormal series $\mathrm{SAR}_{i t}^{\prime}$, where $R_{i t} \in\{1, \ldots, T\}$, for all $t=1, \ldots, T$ and $i=1, \ldots, n$. With assumption 1 and under the null hypothesis of no event effect, each value of $R_{i t}$ is equally likely, implying $P\left[R_{i t}=k\right]=1 / T$, for all $k=1, \ldots, T$. That is, the ranks have a discrete uniform distribution between values 1 and $T$, for which the expectation and variance are

$$
E\left[R_{i t}\right]=\frac{T+1}{2}
$$

and

$$
\operatorname{var}\left[R_{i t}\right]=\frac{T^{2}-1}{12}
$$

Because each observation is associated to a unique rank, the ranks are not independent. ${ }^{4}$ It is straightforward to show that the covariance of the ranks is [see e.g., Gibbons and

\footnotetext{
${ }^{4}$ Thus, if abnormal return $A R_{i t}$ has a rank value $R_{i t}=m$, then a return at any other time point can have any other rank value of the remaining $T-1$ ones, again equally likely.
} 
Chakraborti (1992)]

$$
\operatorname{cov}\left[R_{i t}, R_{i s}\right]=-\frac{(T+1)}{12}
$$

With these results we can derive the major statistical properties of the cumulative ranks [these and more general moment properties can also be found from classics of Wilcoxon (1945) and Mann and Whitney (1947)].

Cumulative ranks for individual return series are defined as

$$
S_{i}\left(\tau_{1}, \tau_{2}\right)=\sum_{t=\tau_{1}}^{\tau_{2}} R_{i t}
$$

where $i=1, \ldots, n$ and $T_{1}<\tau_{1} \leq \tau_{2} \leq T_{2}$. Using (7), the expectation of the cumulative rank is

$$
E\left[S_{i}\left(\tau_{1}, \tau_{2}\right)\right]=\tau \frac{T+1}{2}
$$

where $\tau=\tau_{2}-\tau_{1}+1$ is the number of event days over which $S_{i}\left(\tau_{1}, \tau_{2}\right)$ is accumulated.

Because

$$
\operatorname{var}\left[S_{i}\left(\tau_{1}, \tau_{2}\right)\right]=\sum_{t=\tau_{1}}^{\tau_{2}} \operatorname{var}\left[R_{i t}\right]+\sum_{t=\tau_{1}}^{\tau_{2}} \sum_{\substack{s=\tau_{1} \\ s \neq t}}^{\tau_{2}} \operatorname{cov}\left[R_{i t}, R_{i s}\right],
$$

using equations (8) and (9) it is straightforward to show that the variance of cumulative ranks is

$$
\operatorname{var}\left[S_{i}\left(\tau_{1}, \tau_{2}\right)\right]=\frac{\tau(T-\tau)(T+1)}{12}
$$

where $\tau=1, \ldots, T$.

In particular if the available observation on the estimation period vary from one series to 
another it is more convenient to deal with scaled ranks. Following Corrado and Zivney (1992) we define:

Definition 1 Scaled ranks are defined as

$$
K_{i t}=R_{i t} /(T+1)
$$

Utilizing the above results for unscaled ranks, we immediately obtain from (7), (8), and (9) following proposition:

Proposition 1 Under the null hypothesis of no event effect the expectation, variance, and covariance of the scaled ranks defined in (14) are

$$
\begin{gathered}
E\left[K_{i t}\right]=\frac{1}{2}, \\
\sigma_{K}^{2}=\operatorname{var}\left[K_{i t}\right]=\frac{T-1}{12(T+1)},
\end{gathered}
$$

and

$$
\operatorname{cov}\left[K_{i t}, K_{i s}\right]=-\frac{1}{12(T+1)},
$$

where $i=1, \ldots, n, t \neq s$ and $s, t=1, \ldots, T$.

Remark 1 An important result of Proposition 1 is that the due to the (discrete) uniform null distribution of the rank numbers with $P\left(K_{i t}=t /(T+1)\right)=1 / T, t=1, \ldots T$, the expected value and the variance of the (scaled) ranks exactly match the sample mean and the sample variance. That is,

$$
\bar{K}_{i}=\frac{1}{T} \sum_{t=T_{0}+1}^{T_{2}} K_{i t}=\frac{1}{2}=E\left[K_{i t}\right]
$$


and

$$
s_{K_{i}}^{2}=\frac{1}{T} \sum_{t=T_{0}+1}^{T_{2}}\left(K_{i t}-\frac{1}{2}\right)^{2}=\frac{T-1}{12(T+1)}=\operatorname{var}\left[K_{i t}\right] .
$$

Next we define the cumulative scaled ranks of individual stocks.

Definition 2 The cumulative scaled ranks of a stock $i$ over the event days window form $\tau_{1}$ to $\tau_{2}$ are defined as

$$
U_{i}\left(\tau_{1}, \tau_{2}\right)=\sum_{t=\tau_{1}}^{\tau_{2}} K_{i t}
$$

where $T_{1}<\tau_{1} \leq \tau_{2} \leq T_{2}$.

The expectation and variance of $U_{i}\left(\tau_{1}, \tau_{2}\right)\left[=S_{i}\left(\tau_{1}, \tau_{2}\right) /(T+1)\right]$ are again obtained directly by using (11) and (12). The results are summarized in the following proposition:

Proposition 2 The expectation and variance of the cumulative scaled ranks under the null hypothesis of no event effect are

$$
\mu_{i}\left(\tau_{1}, \tau_{2}\right)=E\left[U_{i}\left(\tau_{1}, \tau_{2}\right)\right]=\frac{\tau}{2}
$$

and

$$
\sigma_{i}^{2}\left(\tau_{1}, \tau_{2}\right)=\operatorname{var}\left[U_{i}\left(\tau_{1}, \tau_{2}\right)\right]=\frac{\tau(T-\tau)}{12(T+1)}
$$

where $i=1, \ldots, n, T_{1}<\tau_{1} \leq \tau_{2} \leq T_{2}$, and $\tau=\tau_{2}-\tau_{1}+1$.

Rather than investigating individual (cumulative) returns, the practice in event studies is to aggregate the individual returns into equally weighted portfolios such that: 
Definition 3 The cumulative scaled ranks is defined as the equally weighted portfolio of the individual cumulative standardized ranks defined in (20),

$$
\bar{U}\left(\tau_{1}, \tau_{2}\right)=\frac{1}{n} \sum_{i=1}^{n} U_{i}\left(\tau_{1}, \tau_{2}\right),
$$

or equivalently

$$
\bar{U}\left(\tau_{1}, \tau_{2}\right)=\sum_{t=\tau_{1}}^{\tau_{2}} \bar{K}_{t}
$$

where $T_{1}<\tau_{1} \leq \tau_{2} \leq T_{2}$ and

$$
\bar{K}_{t}=\frac{1}{n} \sum_{i=1}^{n} K_{i t}
$$

is the time $t$ average of scaled ranks.

The expectation is the same as the expectation of cumulative ranks of individual securities, because

$$
E\left[\bar{U}\left(\tau_{1}, \tau_{2}\right)\right]=\frac{1}{n} \sum_{i=1}^{n} E\left[U_{i}\left(\tau_{1}, \tau_{2}\right)\right]=\frac{\tau}{2} .
$$

If the event days are not clustered the cross-correlations of the return series are zero (or at least negligible). In such a case the variance of (23) is straightforward to calculate. The situation is not much more complicated, if the event days are clustered which implies crosscorrelation. In such a case, recalling that the variances of $U_{i}\left(\tau_{1}, \tau_{2}\right)$ given in equation $(22)$ are constants (independent of $i$ ), we can write the cross-covariance of $U_{i}\left(\tau_{1}, \tau_{2}\right)$ and $U_{j}\left(\tau_{1}, \tau_{2}\right)$ as

$$
\operatorname{cov}\left[U_{i}\left(\tau_{1}, \tau_{2}\right), U_{j}\left(\tau_{1}, \tau_{2}\right)\right]=\frac{\tau(T-\tau)}{12(T-1)} \rho_{i j}\left(\tau_{1}, \tau_{2}\right),
$$

where $\rho_{i j}\left(\tau_{1}, \tau_{2}\right)$ is the cross-correlation of $U_{i}\left(\tau_{1}, \tau_{2}\right)$ and $U_{j}\left(\tau_{1}, \tau_{2}\right), i, j=1, \ldots, n$. Utilizing 
this and the variance-of-a-sum formula, we obtain straightforwardly

$$
\begin{aligned}
\operatorname{var}\left[\bar{U}\left(\tau_{1}, \tau_{2}\right)\right] & =\operatorname{var}\left[\frac{1}{n} \sum_{i=1}^{n} U_{i}\left(\tau_{1}, \tau_{2}\right)\right] \\
& =\frac{1}{n^{2}} \sum_{i=1}^{n} \operatorname{var}\left[U_{i}\left(\tau_{1}, \tau_{2}\right)\right]+\frac{1}{n^{2}} \sum_{i=1}^{n} \sum_{j \neq i}^{n} \operatorname{cov}\left[U_{i}\left(\tau_{1}, \tau_{2}\right), U_{j}\left(\tau_{1}, \tau_{2}\right)\right] \\
& =\frac{1}{n^{2}} \sum_{i=1}^{n} \frac{\tau(T-\tau)}{12(T-1)}+\frac{1}{n^{2}} \sum_{i=1}^{n} \sum_{j \neq i}^{n} \frac{\tau(T-\tau)}{12(T-1)} \rho_{i j}\left(\tau_{1}, \tau_{2}\right) \\
& =\frac{\tau(T-\tau)}{12(T+1) n}\left(1+(n-1) \bar{\rho}_{n}\left(\tau_{1}, \tau_{2}\right)\right),
\end{aligned}
$$

where

$$
\bar{\rho}_{n}\left(\tau_{1}, \tau_{2}\right)=\frac{1}{n(n-1)} \sum_{i=1}^{n} \sum_{\substack{j=1 \\ j \neq i}}^{n} \rho_{i j}\left(\tau_{1}, \tau_{2}\right)
$$

is the average cross-correlation of the cumulated ranks. This is the main result of this sections to be utilized later. Therefore, we summarize it in the following theorem:

Theorem 1 Under the null hypothesis of no event effect the expectation and variance of the average cumulated scaled ranks $\bar{U}\left(\tau_{1}, \tau_{2}\right)$, defined in (23), are

$$
E\left[\bar{U}\left(\tau_{1}, \tau_{2}\right)\right]=\frac{\tau}{2}
$$

and

$$
\operatorname{var}\left[\bar{U}\left(\tau_{1}, \tau_{2}\right)\right]=\frac{\tau(T-\tau)}{12(T+1) n}\left(1+(n-1) \bar{\rho}_{n}\left(\tau_{1}, \tau_{2}\right)\right)
$$

where $\tau=\tau_{2}-\tau_{1}+1, T_{1}<\tau_{1} \leq \tau_{2} \leq T_{2}$, and $\bar{\rho}_{n}\left(\tau_{1}, \tau_{2}\right)$ is defined in (28).

$>$ From practical point of view a crucial result in Theorem 1 is that the only unknown parameter to be estimated is the average cross-correlation $\bar{\rho}_{n}\left(\tau_{1}, \tau_{2}\right)$. There are potentially 
several different ways to estimate the cross-correlation. An obvious and straightforward strategy is to construct first $\tau$ period multi-day series from individual scaled rank series and compute the average cross-correlation of them. This is, however, computationally expensive. The situation simplifies materially if we assume that the cross-correlation of cumulated ranks are the same as the cross-correlation of single day correlations. As will be seen in such a case the average cross-correlation becomes estimated implicitly by using a suitable variance estimator.

\section{Test Statistics for Cumulative Ranks}

If the event periods are non-clustered the returns can be assumed cross-sectionally independent in particular in the event period and thus the variance of the average cumulative $\operatorname{ranks} \bar{U}\left(\tau_{1}, \tau_{2}\right)$ defined in equation (23) reduces to var $\left[\bar{U}\left(\tau_{1}, \tau_{2}\right)\right]=\tau(T-\tau) /(12(T+1) n)$ in equation (30). Thus, in order to test the null hypothesis of no even mean effect which in terms of the ranks reduces to testing the hypothesis,

$$
H_{0}: \mu\left(\tau_{1}, \tau_{2}\right)=\frac{1}{2} \tau
$$

an appropriate $z$-ratio (called hereafter CUMRANK-Z) is

$$
Z_{1}=\frac{\bar{U}\left(\tau_{1}, \tau_{2}\right)-\frac{1}{2} \tau}{\sqrt{\frac{\tau(T-\tau)}{12(T+1) n}}} .
$$

This is the same statistic as $T_{R}^{*}$ proposed in Corrado and Truong (2008, p. 504) with nonscaled ranks.

Remark 2 If the series are of different lengths such that there are $T^{i}$ observations available 
for series $i$, the average

$$
\overline{\operatorname{var}}\left[\bar{U}\left(\tau_{1}, \tau_{2}\right) ; \bar{\rho}_{n}\left(\tau_{1}, \tau_{2}\right)=0\right]=\frac{1}{n} \sum_{i=1}^{n} \frac{\tau\left(T^{i}-\tau\right)}{12\left(T^{i}+1\right) n}
$$

is recommended to use in place of $\tau(T-\tau) /(12(T+1) n)$ in the denominator of $(32)$.

In spite that the theoretical variance is known when the ranks are cross-sectionally independent, Corrado and Zivney (1992) propose to estimate the variance for the event day average standardized rank $\bar{K}_{t}$ defined in equation (25) by the sample variance of the equally weighted portfolio

$$
\tilde{s}_{\bar{K}}^{2}=\widehat{\operatorname{var}}\left[\bar{K}_{t}\right]=\frac{1}{T} \sum_{t=T_{0}+1}^{T_{2}} \frac{n_{t}}{n}\left(\bar{K}_{t}-\frac{1}{2}\right)^{2},
$$

where $T=T_{2}-T_{0}$ is the combined length of the estimation period and the event period and $n_{t}$ is the number of observations in the mean $\bar{K}_{t}$ at time point $t$. As we will discuss later, an advantage of the sample estimator over the theoretical variance is that it is more robust than the the theoretical variance to possible cross-sectional correlation of the returns. Cross-sectional correlation is in particular an issue when the event days are clustered. The results in Kolari and Pynnönen (2010) show that already a small cross-correlation seriously biases the test results if not properly accounted for.

In terms of the estimator in (34), the variance of the cumulative ranks $\bar{U}\left(\tau_{1}, \tau_{2}\right)$ is estimated in practice by simply ignoring the serial dependency between and rank numbers and multiplying the single day rank variance by the length of the accumulated ranks such that

$$
\tilde{s}^{2}\left(\tau_{1}, \tau_{2}\right)=\frac{\tau}{T} \sum_{t=T_{0}+1}^{T_{2}} \frac{n_{t}}{n}\left(\bar{K}_{t}-\frac{1}{2}\right)^{2}=\tau \tilde{s}_{\bar{K}}^{2} .
$$


The implied z-ratio for testing the null hypothesis in (31) is

$$
Z_{2}=\frac{\bar{U}\left(\tau_{1}, \tau_{2}\right)-\frac{1}{2} \tau}{\sqrt{\tau} \tilde{s}_{\bar{K}}}
$$

This statistic for testing cumulative abnormal returns by the rank statistic is suggested in Campbell and Wasley (1993, p. 85), and we call it CAMPBELL-WASLEY hereafter. For a single day return the statistic reduces to the single period rank test suggested in Corrado (1989) and Corrado and Zivney (1992).

However, as we will demonstrate below, the autocorrelation between the ranks implies slight downward bias into the variance estimator $\tilde{s}^{2}\left(\tau_{1}, \tau_{2}\right)$. The bias increases as the length, $\tau=\tau_{2}-\tau_{1}+1$, of the period over which the ranks are accumulated, grows. Also, for fixed $T$ the asymptotic distributions of CUMRANK-Z and CAMPBELL-WASLEY (as well as Corrado's single period rank test) prove to be theoretically quite different.

It is straightforward to show that the variance estimator $\tilde{s}^{2}\left(\tau_{1}, \tau_{2}\right)$ in $(35)$, utilized in the CAMPBELL-WASLEY statistic $Z_{2}$ in (36), is a biased estimator of the population variance $\operatorname{var}\left[\bar{U}\left(\tau_{1}, \tau_{2}\right)\right]$ in equation (30). Assuming $n_{t}=n$ for all $t$, the bias can be computed, because $\operatorname{var}\left[\bar{K}_{t}\right]=E\left[\left(\bar{K}_{t}-1 / 2\right)^{2}\right]$ such that

$$
E\left[\tilde{s}^{2}\left(\tau_{1}, \tau_{2}\right)\right]=\frac{\tau}{T} \sum_{t=T_{0}+1}^{T_{1}} E\left[\left(\bar{K}_{t}-1 / 2\right)^{2}\right]=\frac{\tau}{T} \sum_{t=T_{0}+1}^{T_{1}} \operatorname{var}\left[\bar{K}_{t}\right]
$$

Utilizing then equation (30) with $\tau_{1}=\tau_{2}$ (in the equation), we obtain:

Proposition 3 Assuming $n_{t}=n$ for all $t=T_{0}+1, \ldots, T_{1}$, then under the null hypothesis 
of no event effects the expected value of $\tilde{s}^{2}\left(\tau_{1}, \tau_{2}\right)$ defined in (35) is

$$
E\left[\tilde{s}^{2}\left(\tau_{1}, \tau_{2}\right)\right]=\frac{\tau(T-1)}{12(T+1) n}\left(1+(n-1) \bar{\rho}_{n}\right)
$$

and the bias is

$$
\begin{aligned}
\operatorname{Bias}\left[\tilde{s}^{2}\left(\tau_{1}, \tau_{2}\right)\right]= & E\left[\tilde{s}^{2}\left(\tau_{1}, \tau_{2}\right)\right]-\sigma^{2}\left(\tau_{1}, \tau_{2}\right) \\
= & \frac{\tau(\tau-1)}{12(T+1) n}\left[1+(n-1) \bar{\rho}_{n}\right] \\
& +\frac{\tau(T-\tau)}{12(T+1) n}\left\{1+(n-1)\left[\bar{\rho}_{n}-\bar{\rho}_{n}\left(\tau_{1}, \tau_{2}\right)\right]\right\}
\end{aligned}
$$

where $\bar{\rho}_{n}$ is the average cross-correlation of the single day ranks $K_{i t}$ and $\bar{\rho}_{n}\left(\tau_{1}, \tau_{2}\right)$ is the average cross-correlation of $\tau=\tau_{2}-\tau_{1}+1$ period cumulated ranks.

In practice the the average cross-correlation, $\bar{\rho}_{n}$, of the single day ranks and the average cross-correlation, $\bar{\rho}_{n}\left(\tau_{1}, \tau_{2}\right)$ of $\tau$-period cumulated ranks is likely to be approximately the same, i.e., $\bar{\rho}_{n}\left(\tau_{1}, \tau_{2}\right) \approx \bar{\rho}_{n}$, such that the bias reduces to

$$
\operatorname{Bias}\left[\tilde{s}^{2}\left(\tau_{1}, \tau_{2}\right)\right]=\frac{\tau(\tau-1)}{12(T+1) n}\left[1+(n-1) \bar{\rho}_{n}\right]
$$

In this case the bias is easily fixed by multiplying $\tilde{s}^{2}\left(\tau_{1}, \tau_{2}\right)$ defined in equation (35) by the factor $(T-\tau) /(T-1)$ yielding an estimator

$$
\hat{s}^{2}\left(\tau_{1}, \tau_{2}\right)=\frac{\tau(T-\tau)}{T(T-1)} \sum_{t=T_{0}+1}^{T_{2}} \frac{n_{t}}{n}\left(\bar{K}_{t}-\frac{1}{2}\right)^{2}=\frac{T-\tau}{T-1} \tilde{s}^{2}\left(\tau_{1}, \tau_{2}\right) .
$$

Utilizing this correction gives a modification of the CAMPBELL-WASLEY statistic, such that

$$
Z_{2}^{\prime}=\frac{\bar{U}\left(\tau_{1}, \tau_{2}\right)-\frac{1}{2} \tau}{\hat{s}\left(\tau_{1}, \tau_{2}\right)}=\sqrt{\frac{T-1}{T-\tau}} Z_{2}
$$


Rather than using this, the small sample distributional properties (in terms of the number of time series observations, $T$ ) turn out to better by using the following modified statistic, which we call CUMRANK-T

$$
t_{\text {cumrank }}=Z_{2}^{\prime} \sqrt{\frac{T-2}{T-1-\left(Z_{2}^{\prime}\right)^{2}}} .
$$

An advantage of the above CUMRANK-T statistic over the CUMRANK-Z statistic, $Z_{1}$, defined in equation (32), is its better robustness against cross-sectional correlation, because the variance estimator in equation (40), which is used in the denominator, implicitly accounts the possible cross-correlation. The price, however, is the loss of some power. Also for fixed $T$ the asymptotic distributions of these statistics are different.

3.1 Asymptotic Distributions of the CUMRANK-Z, CAMPBELL-WASLEY, and CUMRANKT Statistics: Independent Observations

In event studies asymptotics can be dealt with both in time series and in cross-section dimensions. In the former the length of the estimation period is increasing while in the latter the number of firms is allowed to increase towards infinity. In most cases the interest is in the latter when the number of firms, $n$, is increasing. We adopt also this convention and assume that all series in the sample have a fixed number $T=T_{2}-T_{0}$ time series observations such there are no missing returns. Furthermore, we assume first that the event days are non-clustered such that the event period observations, in particular, are cross-sectionally independent. Then under the null hypothesis the average cumulative rank $\bar{U}\left(\tau_{1}, \tau_{2}\right)$ defined in equation (23) is a sum of independent and identically distributed random variables, $U_{i}\left(\tau_{1}, \tau_{2}\right)$, 
that have identical means, $E\left[U_{i}\left(\tau_{1}, \tau_{2}\right)\right]=\tau / 2$, and identical variances, $\operatorname{var}\left[U_{i}\left(\tau_{1}, \tau_{2}\right)\right]=$ $\tau(T-\tau) /(12(T+1))$. Thus, under the null hypothesis the cumulated ranks $U_{i}\left(\tau_{1}, \tau_{2}\right)$ are independent and identically distributed random such that the Central Limit Theorem (CLT) can be applied, and we have the following results.

Theorem 2 (Asymptotic normality of CUMRANK-Z): If the the even days are non-clustered such that the cumulative standardized ranks $U_{i}\left(\tau_{1}, \tau_{2}\right)$ defined in $(20)$ are independent and identically distributed random variables with mean $E\left[U_{i}\left(\tau_{1}, \tau_{2}\right)\right]=\tau / 2$ and variance $\operatorname{var}\left[U_{i}\left(\tau_{1}, \tau_{2}\right)\right]=$ $\tau(T-\tau) /(12(T+1)), i=1, \ldots, n$, then under the null hypothesis of no event effect, as $n \rightarrow \infty$

$$
Z_{1}=\frac{\bar{U}\left(\tau_{1}, \tau_{2}\right)-\tau / 2}{\sigma\left(\tau_{1}, \tau_{2}\right)} \stackrel{d}{\rightarrow} N(0,1)
$$

where

$$
\sigma\left(\tau_{1}, \tau_{2}\right)=\sqrt{\operatorname{var}\left[\bar{U}\left(\tau_{1}, \tau_{2}\right) ; \bar{\rho}_{n}\left(\tau_{1}, \tau_{2}\right)=0\right]}=\sqrt{\frac{\tau(T-\tau)}{12(T+1) n}}
$$

$T_{0}<\tau_{1} \leq \tau_{2} \leq T_{2}, T=T_{2}-T_{0}, \tau=\tau_{2}-\tau_{1}+1$, and $\stackrel{\text { "d }}{\rightarrow}$ "denotes convergence in distribution.

Proofs of the following theorems regarding the asymptotic distributions of $Z_{2}^{\prime}$ (modified CAMBELL-WASLEY) and CUMRANK-T defined in equations (41) and (42), respectively, are presented in Appendix.

Theorem 3 (Asymptotic distribution of modified CAMPBELL-WASLEY): For a fixed T, under the assumption of cross-sectional independence, the density function of the asymptotic 
distribution of the modified CAMBELL-WASLEY statistic $Z_{2}^{\prime}$ defined in equation (41) when $n \rightarrow \infty$, is

$$
f_{Z_{2}^{\prime}}(z)=\frac{\Gamma[(T-1) / 2]}{\Gamma[(T-2) / 2] \sqrt{(T-1) \pi}}\left(1-\frac{z^{2}}{T-1}\right)^{\frac{1}{2}(T-2)-1}
$$

for $|z| \leq \sqrt{T-1}$ and zero elsewhere, where $\Gamma(\cdot)$ is the Gamma function.

The distribution of the $Z_{2}$ statistic defined in equation (36) is obtained via the transformation in equation (41).

Theorem 4 (Asymptotic distribution of CUMRANK-T): Under the assumptions of Theorem 3,

$$
t_{\text {cumrank }}=Z_{2}^{\prime} \sqrt{\frac{T-2}{T-1-\left(Z_{2}^{\prime}\right)^{2}}} \stackrel{d}{\rightarrow} t_{T-2},
$$

as $n \rightarrow \infty$, where $Z_{2}^{\prime}$ is defined in equation (41) and $t_{T-2}$ denotes the Student $t$-distribution with $T-2$ degrees of freedom.

Thus, Theorem 3 implies that $\left(Z_{2}^{\prime}\right)^{2} /(T-1)$ is Beta distributed with parameters $1 / 2$ and $(T-2) / 2$. However, using the fact that

$$
\left(1-\frac{z^{2}}{T-1}\right)^{\frac{1}{2}(T-2)-1} \rightarrow e^{-\frac{1}{2} z^{2}}
$$

as $T \rightarrow \infty$ and that the $t$-distribution approaches the $N(0,1)$-distribution as the degrees of freedom $T-2$ increases, we find that for large $T$ all the null distributions of the statistics $Z_{1}, Z_{2}, Z_{2}^{\prime}$, and $t_{\text {cumrank }}$ can be approximated by the standard normal distribution. 


\subsection{Asymptotic Distributions: Cross-Sectional Dependence (Clustered Event Days)}

Cross-sectional dependence due to clustered event days (the same event days across the firms) changes materially the asymptotic properties of the test statistics like CUMRANK-Z defined in equation (32) that do not account the dependence.

However, as stated in Lehmann (1999, Sec. 2.8), it is still frequently true that the asymptotic normality holds provided that the average cross-correlation, $\bar{\rho}_{n}\left(\tau_{1}, \tau_{2}\right)$, tend to zero rapidly enough such that

$$
\frac{1}{n} \sum_{i=1}^{n} \sum_{i \neq j} \rho_{i j}\left(\tau_{1}, \tau_{2}\right) \rightarrow \gamma
$$

as $n \rightarrow \infty$.

In financial applications this would be the case if there were a finite number of firms in each industry and the return correlations between industries were zero. This is a special case of so called $m$-independence. Generally, a sequence of random variables $X_{1}, X_{2}, \ldots$, is said to be $m$-independent, if $X_{i}$ and $X_{j}$ are independent if $|i-j|>m$. In cross-sectional analysis this would mean that the variables can be ordered such that when the index difference is larger than $m$ the variables are independent.

Thus, assuming that $U_{i}\left(\tau_{1}, \tau_{2}\right)$ defined in equation (20) are $m$-independent, $i=1,2, \ldots, n$, $(n>m)$ then the correlation matrix of $U_{1}\left(\tau_{1}, \tau_{2}\right), \ldots, U_{n}\left(\tau_{1}, \tau_{2}\right)$ is band-diagonal such that all $\rho_{i j}$ with $|i-j|>m$ are zeros. It is straightforward to see that in such a correlation matrix there are $m(2 n-m-1)$ nonzero correlations in addition to the $n$ ones on the diagonal. Thus, 
in the double summation (48) there are $m(2 n-m-1)$ non-zero elements, and we can write

$$
\frac{1}{n} \sum_{i=1}^{n} \sum_{\substack{j=1 \\ j \neq i}}^{n} \rho_{i j}\left(\tau_{1}, \tau_{2}\right)=\frac{m(2 n-m-1)}{n} \tilde{\rho}_{n}\left(\tau_{1}, \tau_{2}\right) \rightarrow \gamma
$$

where $\tilde{\rho}_{n}\left(\tau_{1}, \tau_{2}\right)$ is the average of the $m(2 n-m-1)$ cross-correlations in the band-diagonal correlations matrix and $\gamma=2 m \tilde{\rho}\left(\tau_{1}, \tau_{2}\right)$ is a finite constant with $\tilde{\rho}\left(\tau_{1}, \tau_{2}\right)=\lim _{n \rightarrow \infty} \tilde{\rho}_{n}\left(\tau_{1}, \tau_{2}\right)$ and $2 m=\lim _{n \rightarrow \infty} m(2 n-m-1) / n$.

Thus, under the $m$-independence the asymptotic distribution of the CUMRANK-Z statistic is

$$
Z_{1} \rightarrow N(0,1+\gamma)
$$

This implies that although the normality holds, the $Z_{1}$-statistic is not robust to crosssectional correlation of the return series. Typically $\gamma>1$, which means that $Z_{1}$ will tend to over-reject the null hypothesis.

The asymptotic properties of the modified CAMPBELL-WASLEY statistic, $Z_{2}^{\prime}$ (as well as $Z_{2}$ ), and the CUMRANK-T statistic, $t_{\text {cumrank }}$ in this regard are quite different to that of CUMRANK-Z. The reason is that these statistics are invariant to scaling of observations. This implies that the limiting distributions of the (modified) CAMPBELL-WASLEY statistic and the CUMRANK-T statistic turn out to apply as such also under the $m$-independence. This follows simply from the fact that if the asymptotic normality holds under the $m$ independence such that the limiting correlation effect is $1+\gamma$, then using the scaled variables, $\left(K_{i t}-1 / 2\right) / \sqrt{1+\gamma}$, in place of the original variables, the test statistics remain intact and all the results in Appendix follow and, hence, the results in Theorem 3 and Theorem 4. 


\section{Simulation Designs}

We adopt the well-known simulation approach presented by Brown and Warner (1980), and widely used in several other methodological studies [e.g. Brown and Warner (1985), Corrado (1989), Cowan (1992), Campbell and Wasley (1993) and Cowan and Sergeant (1996)]. Hence we conduct a simulation study to investigate the empirical behavior of the rank test introduced in section 3 and compare the new rank statistic against the ordinary $t$-test, Patell t-test, BMP $t$-test and the non-parametric test statistics presented by Corrado and Truong (2008) and Campbell and Wasley (1993).

\subsection{Sample Construction}

When conduct the simulation study by selecting 1,000 samples of $n=50$ return series with replacement from our data base, which includes daily returns from stocks belonging to S\&P 400, S\&P 500 and S\&P 600 indexes. Each time a security is selected, a hypothetical event day is generated. The events are assumed to occur with equal probability on each trading day. The event day is denoted as day 0 . We report the results for event day $t=0$ abnormal return $\operatorname{AR}(0)$ together with cumulative abnormal returns $\mathrm{CAR}(-1,+1), \mathrm{CAR}(-5,+5)$ and CAR $(-10,+10)$. Our estimation period is comprised of 239 days prior to the event period (the days from -249 to -11 ) and our event period is comprised of 21 days (the days -10 to +10$)$. Therefore, the estimation period and the event period altogether consist of 260 days, which is approximately one year in calendar time. For a security to be included to the sample, there should be no missing return data in the last 30 days, i.e., in days -19 to +10 . 
Charest (1978), Mikkelson (1981), Penman (1982) and Rosenstein and Wyatt (1990) have found that the event period standard deviation is about 1.2 to 1.5 times the estimation period standard deviation. For that reason we also investigate event-induced volatility effects on the test statistics. Correspondingly we introduce increased volatility by multiplying CARperiod returns by the factor $\sqrt{c}$, with values $c=1.5$ for an approximate 20 percent increased volatility $^{5}, c=2.0$ for an approximate 40 percent increased volatility ${ }^{6}$ and $c=3.0$ for an approximate 70 percent increased volatility ${ }^{7}$ due to the event effect. To add realism we generate the volatility factors $c$ for each stock based on the following uniform distributions $U[1,2], U[1.5,2.5]$ or $U[2.5,3.5]$. This generate on average the variance effects of $1.5,2.0$ and 3.0. Furthermore for the no volatility effect experiment we fix $c=1.0$. This procedure increases the volatility of each return on the event day by random amount.

The power properties of the tests are investigated empirically by adding an abnormal return between -3 percent and +3 percent on the cumulated returns. We divide the abnormal return by the number of the days in the CAR and add the fraction into each of the returns within the CAR-window, such that the aggregated effect adds to the abnormal return. For example, in a $\mathrm{CAR}(-5,+5)$ an abnormal return of +2 percent is divided by 11 and the fraction $2 / 11$ is added into each of the returns within the 11-day window making up $\mathrm{CAR}(-5,+5)$. By this we aim to mimic the information leakage and delayed adjustment, discussed in the introduction section of the paper. That is, if the markets are inefficient information may leak before the event which shows up as abnormal behavior before the event

\footnotetext{
${ }^{5}$ because $\sqrt{1.5} \approx 1.2$.

${ }^{6}$ because $\sqrt{2.0} \approx 1.4$.

${ }^{7}$ because $\sqrt{3.0} \approx 1.7$.
} 
day. Delays in the event information processing show up as abnormal return behavior after the event day.

In order to investigate the impact of the length of the estimation period on the performance of the test statistics, we repeat core simulations by using estimation periods of 25,50 , and 100 days in addition to the 239-day estimation period on which the main results of the paper are build. According to Peterson (1989), typical lengths of the estimation period for daily studies range from 100 to 300 days within which our base length of 239 days belongs to. As stated in Peterson (1989), when selecting the length of the estimation period one must weigh the benefits of a longer period and its potential improved prediction model and the cost of the longer period.

Finally, we also study the effect of event-date clustering on the test statistics. For example, Kolari and Pynnönen (2010) state that it is well known that event studies are prone to crosssectional correlation among abnormal returns when the event day is the same for sample firms. They also showed that even when the average cross-correlation is relatively low, the effects are serious in terms of over-rejecting the true null hypothesis of zero average abnormal return.

\subsection{Abnormal Return Model}

There is a number of approaches available to calculate the normal return of a given security. 
We define the abnormal behavior of security returns with the help of market model

$$
r_{i t}=\alpha_{i}+\beta_{i} r_{m t}+\epsilon_{i t}
$$

where again $r_{i t}$ is the return of stock $i$ at time $t, r_{m t}$ is the market index return at time $t$ and $\epsilon_{i t}$ is a white noise random component, which is not correlated with $r_{m t}$. In the market model the market index return is replaced by the S\&P 500-index return in our simulation study. Then the resulting abnormal returns are obtained as difference of the realized and the predicted returns as follows

$$
\mathrm{AR}_{i t}=r_{i t}-\left(\hat{\alpha}_{i}+\hat{\beta}_{i} r_{m t}\right)
$$

where the parameters are estimated from the estimation period with ordinary least squares. According to Campbell, Lo and MacKinley (1997) the market model represents a potential improvement over the traditional constant-mean-return model, because by removing the portion of the return that is related to variation in the market's return, the variance of the abnormal return is reduced. This can lead to increased ability to detect event effects.

\subsection{Test Statistics}

In addition of the notations in Section 2, the standardized cumulative abnormal return (SCAR) is defined as

$$
\operatorname{SCAR}_{i}\left(\tau_{1}, \tau_{2}\right)=\frac{\operatorname{CAR}_{i}\left(\tau_{1}, \tau_{2}\right)}{S_{\mathrm{CAR}_{i}\left(\tau_{1}, \tau_{2}\right)}},
$$

where $S_{\mathrm{CAR}_{i}\left(\tau_{1}, \tau_{2}\right)}$ is the standard deviation of the cumulative abnormal returns adjusted for forecast error [see Campbell, Lo and MacKinlay (1997, Section 4.4.3)]. 
The ordinary $t$-test (ORDIN) is defined as

$$
t_{\text {ordin }}=\frac{\overline{\mathrm{CAR}}\left(\tau_{1}, \tau_{2}\right)}{\operatorname{s.e}\left(\overline{\mathrm{CAR}}\left(\tau_{1}, \tau_{2}\right)\right)}
$$

where

$$
\overline{\operatorname{CAR}}\left(\tau_{1}, \tau_{2}\right)=\frac{1}{n} \sum_{i=1}^{n} \operatorname{CAR}_{i}\left(\tau_{1}, \tau_{2}\right)
$$

and $s . e\left(\overline{\mathrm{CAR}}\left(\tau_{1}, \tau_{2}\right)\right)$ is the standard error of the average cumulative abnormal return $\overline{\mathrm{CAR}}\left(\tau_{1}, \tau_{2}\right)$ adjusted for the prediction error [see again Campbell, Lo and MacKinlay (1997, Section 4.4.3)]. ORDIN test statistic is asymptotically $N(0,1)$-distributed under the null hypothesis of no event effect.

Patell (1976) test statistic is

$$
t_{\mathrm{patell}}=\sqrt{\frac{n\left(L_{1}-4\right)}{L_{1}-2}} \overline{\mathrm{SCAR}}_{\tau}
$$

where $L_{1}=T_{1}-T_{0}$ is the length of the estimation period, $\overline{\operatorname{SCAR}}\left(\tau_{1}, \tau_{2}\right)$ is the average of the standardized CAR defined in equation (53). Also Patell test statistic is asymptotically $N(0,1)$-distributed under the null hypothesis.

The Boehmer, Musumeci and Poulsen (BMP) (1991) test statistics is

$$
t_{\mathrm{bmp}}=\frac{\overline{\operatorname{SCAR}}\left(\tau_{1}, \tau_{2}\right) \sqrt{n}}{S_{\operatorname{SCAR}\left(\tau_{1}, \tau_{2}\right)}}
$$

where $S_{\mathrm{SCAR}}$ is the cross-sectional standard deviation of SCARs defined as

$$
S_{\operatorname{SCAR}\left(\tau_{1}, \tau_{2}\right)}=\sqrt{\frac{1}{n-1} \sum_{i=1}^{n}\left(\operatorname{SCAR}_{i}\left(\tau_{1}, \tau_{2}\right)-\overline{\operatorname{SCAR}}\left(\tau_{1}, \tau_{2}\right)\right)^{2}}
$$

Again also BMP test statistic is asymptotically $N(0,1)$-distributed under the null hypothesis. 
In addition to these statistics, our simulation study includes also the CUMRANK-Z test statistic $Z_{1}$ given in equation (32), the CAMPBELL-WASLEY statistic $Z_{2}$ defined in equation (36), and the CUMRANK-T statistic $t_{\text {cumrank }}$ defined in equation (42).

\subsection{The Data}

The data in this simulation design consist of daily closing prices of 1,500 the U.S. traded stocks that make up the S\&P 400, S\&P 500, and S\&P 600 indexes. S\&P 400 covers the midcap range of stocks, S\&P 500 the large-cap range of stocks and S\&P 600 the small-cap range of stocks. We have excluded 5 percent of the stocks having the smallest trading volume. Therefore 72 stocks from S\&P 600, two stock from S\&P 400 and one stock from S\&P 500 are excluded. The sample period spans from the beginning of July, 1991 to October 31, 2009. S\&P 400 index was launched in June in 1991 which is why our sample period starts in the beginning of July, 1991. Official holidays and observances are excluded from the data.

The returns are defined as log-returns

$$
r_{i t}=\log \left(P_{i t}\right)-\log \left(P_{i t-1}\right)
$$

where $P_{i t}$ is the closing price for stock $i$ at time $t$.

\section{Results}

The results from the simulation study are presented in this section. First, we present the sample statistics of the abnormal returns, the cumulated abnormal returns and the test 
statistics. Second, the properties of the empirical distributions of the non-parametric tests are presented. Third, the rejection rates are presented. The rejection rates are also presented in cases where the event-induced volatility is present and in the cases where the estimation period is shortened. Finally, the power properties of the test statistics are presented. The rejection rates and power properties are also presented when the event-dates are clustered.

\subsection{Sample statistics}

Table 1 reports sample statistics from 1,000 simulations for the event day abnormal returns, $\operatorname{AR}(0)$, and for the cumulative abnormal returns: $\mathrm{CAR}(-1,+1), \mathrm{CAR}(-5,+5)$, and $\operatorname{CAR}(-10,+10)$. It also reports the sample statistics for the test statistics for $\operatorname{AR}(0)$, $\mathrm{CAR}(-1,+1), \operatorname{CAR}(-5,+5)$ and $\operatorname{CAR}(-10,+10)$. Under the null hypothesis of no event effect all the test statistics should have zero mean and (approximately) unit variance. Considering only the single abnormal returns $\mathrm{AR}(0)$ in Panel A of Table 1, it can be noticed that means of all test statistics are statistically close to zero. For example (in absolute value) the largest mean of -0.024 for the PATELL statistic is only 1.113 standard errors away from zero. In longer event windows the averages of the test statistics, albeit small, start to deviate significantly away from the theoretical value of zero. It is worth to notice that almost in every case the means of the test statistics are negative. It is also worth to notice that the standard deviations of the test statistics are quite close to unity as expected.

[Table 1] 
5.2 Empirical distributions of CUMRANK-Z, CAMBELL-WASLEY and CUMRANK-T

Table 2 reports Cramer-von Mises normality tests for ORDIN, PATELL, BMP, CUMRANKZ, and CAMBELL-WASLEY and Cramer-von Mises test of CUMRANK-T against a $t$ distribution with appropriate degrees of freedom, depending on the length of the estimation period. Departures from normality ( $t$-distribution for CUMRANK-T) of the statistics are typically not statistically significant for $\operatorname{AR}(0)$ and $\operatorname{CAR}(-1,+1)$, i.e., in the short end of cumulated returns. In the long end of cumulated returns (11 and 21 days) the normality is rejected in most of the cases, in particular, for PATELL, BMP, and CAMPBELL-WASLEY. For CUMRANK-Z and CUMRANK-T ( $t$-distribution) the significances are not particularly high by being in some cases significant at the $5 \%$ level and only once at the $1 \%$ level. For ORDIN the normality is rejected only in the case of the shortest estimation period. In all, the results indicate that in particular for short CAR-windows a sample size of $n=50$ series seems to be large enough to warrant satisfactory approximation by the asymptotic normality ( $t$-distribution of CUMRANK-T). A plausible reason for the goodness of normality approximation in the short end of CARs is that the total number of time series observations even with the shortest estimation period of 25 days is in fact 46 days when the estimation period is combined with the 21 event period observations. Thus, the asymptotic result in (47) becomes close enough. With longer CARs of $\operatorname{CAR}(-5,+5)$ and $\operatorname{CAR}(-10,+10)$ the nonnormality of the CAMPBELL-WASLEY, in particular, is most likely due to the increasing bias in the standard error shown in equation (40). This is further illustrated below with the aid of quantile plots. The failing normality of PATELL and BMP with the long CARs is not that clear. 


\section{[Table 2]}

In order to get a closer view of the null-distributions of the non-parametric tests that are the focus of this paper, and for which the paper has derived the new asymptotic distribution results, Figures 1-3 plot empirical quantiles of CUMRANK-Z, CAMPBELL-WASLEY, and CUMRANK-T from 1,000 simulations against theoretical quantiles for $\operatorname{AR}(0), \operatorname{CAR}(-1,+1)$, CAR $(-5,+5)$, and $\operatorname{CAR}(-10,+10)$ under the null hypothesis of no event effect. The test statistics are computed in each simulation using different estimation period lengths indicated in the figures. In Figures 1 and 2 standard normal distribution quantiles are on the vertical axes and on the horizontal axes are the test statistic values, CUMRANK-Z (in Figure 1) and CAMPBELL-WASLEY (in Figure 2). Likewise in Figure 3, which illustrates the distributions of CUMRANK-T statistics, the theoretical quantiles from the Student $t$ distributions with $T-2=258$ degrees of freedom (Theorem 4) are on the vertical axis and the empirical quantiles are on the horizontal axis. If the statistics follow the theoretical distributions the plots should be close to the 45 degree diagonal line. According to Figures 1 and 2 the distributions of the test statistics CUMRANK-Z and CAMPBELL-WASLEY seem to match quite well the theoretical distributions with plots close to the 45 degree lines. Due to the relatively large number of combined estimation and event period observations, the close normality of CAMPBELL-WASLEY is consistent with the discussion related to equation (47). However, as was observed in Section 3, the bias in in the standard error used in CAMPBELLWASLEY increases as the length of the period over which the ranks are cumulated grows. Because this bias is essentially a scaling factor, it explains the tilting effect showing up in Panel CAR $(-10,+10)$ of Figure 2. Regarding the CUMRANK-T statistic, Figure 3 shows 
that empirical distribution matches very closely to the asymptotic Student $t$ distribution of Theorem 4. For longer event windows there is some turbulence with some tail observations that, however, can be accounted to random noise.

Finally, in order to see the effect of the length of the estimation period on the asymptotic distributions to CUMRANK-T and CAMPBELL-WASLEY, in particular, Figures 4-6 show relevant qunatile plots for $\operatorname{AR}(0), \operatorname{CAR}(-1,+1), \operatorname{CAR}(-5,+5)$, and $\operatorname{CAR}(-10,+10)$ for estimation periods 25, 50, and 100 days such that the combined number of observations are $46(=25+21), 71$, and 121 . Figures $4-6$ provide compelling support to the view that the asymptotic $t$-distribution of CUMRANK-T given in Theorem 4 works fine already for $n=50$ firms at all estimation period lengths. The scaling error in the standard error of the CAMPBELL-WASLEY statistic combined with the reducing accuracy of the normal approximation start to show up in particular in the longer CARs $(\mathrm{CAR}(-5,+5)$ and CAR $(-10,+10)$ in CAMPBELL-WASLEY panels of Figures 4-6).

\subsection{Rejection rates}

Table 3 reports the lower tail, upper tail and two-tailed rejection rates (Type I errors) at the 5 percent level under the null hypothesis of no event mean effect. Columns 2-4 of the Table show the results with no event-induced volatility. Almost all rejection rates are close to the nominal rate of 0.05 for short CAR-windows of $\operatorname{AR}(0)$ and $\operatorname{CAR}(-1,+1)$. Only PATELL statistics tends to over-reject the null hypothesis for the two-tailed tests. For the longer CARs of $\operatorname{CAR}(-5,+5)$ and $\operatorname{CAR}(-10,+10)$ all the other test statistics except PATELL 
and CAMPBELL-WASLEY reject close to the nominal rate with rejection rates that are well within the approximate 99 percent confidence interval of $[0.032,0.068]$. For the longer CARs PATELL tends to over-reject in addition of the two-tailed testing also on the lower tail. CAMPBELL-WASLEY statistic tends to under-reject the null hypothesis for longer CARs for the upper tail and the two-tailed tests. It is notable that the rejection rates of the parametric tests of ORDIN and BMP as well as the non-parametric tests of CUMRANK-Z and CUMRANK-T are generally within the approximate 99 percent confidence bound also for the longer CARs.

[Table 3]

Columns 5-13 in Table 3 report the rejection rates under the null hypothesis in the case of event-induced variance. ORDIN and PATELL tests over-reject when the variance increases, which is a well-known outcome. At the highest factor of $c=3.0$ the Type I errors for both ORDIN and PATELL are in the range from 0.20 to 0.30 in two-tailed testing, that is, five to six times the nominal rate. The CAMPBELL-WASLEY statistic again under-rejects the null hypothesis for the right tail and two-tailed tests in the longer CAR-windows. CUMRANK$\mathrm{T}$ seems also to under-reject in two occasions with the longer CARs of $\mathrm{CAR}(-5,+5)$ and CAR $(-10,+10)$ on the upper tail. The lower tail and two-tailed rates, however, are close to the nominal rate. BMP and CUMRANK-Z statistics seem to be well specified at all CARs.

Table 4 reports the impact of the length of the estimation period on the rejection rates. The table reports two-tailed results for Type I errors at the 5 percent level under the null 
hypothesis of no event mean effect when the estimation periods are 25, 50, and 100 days. Generally the rejection rates are not very sensitive to the length of the estimation period. The major exceptions are PATELL and CAMPBELL-WASLEY. The over-rejection of PATELL increases substantially in particular for the long CARs as the estimation period gets shorter. For example, with $\mathrm{CAR}(-10,+10)$ there the empirical rejection rate is 0.134 , almost three times the nominal, when the estimation period is 25 days, while the rate reduces to 0.084 with 100 days, and with 239 days (Table 3, column 4 in Panel D), the rate is 0.075 . The sample size seem also affect substantially to the under-rejection of CAMPBELL-WASLEY in the long CARs. For example, with $\operatorname{CAR}(-10,+10)$ the empirical rejection rate is 0.005 with estimation period length 25 (Table 4, first column in Panel D), which is one tenth of the nominal rate. With 100 days the rejection rate increases to 0.012 , which still is only about one fourth of the nominal rate. From Table 3, (column 4 in Panel D) we see that the rejection rate increases 0.022 , which is about one half of the nominal rate when the estimation period length grows to 239 days. Also ORDIN seems to be sensitive to the length of the estimation period, while BMP, CUMRANK-Z, and CUMRANK-T seem to be quite insensitive to the length of the estimation period.

[Table 4]

5.3 Power of the tests

5.3.1 Non-clustered event days 
The power results of the test statistics for two-tailed tests are shown in Panels A to D of Table 5 and graphically depicted in Figures 7 to 10. The zero abnormal return line in each panel of Table 5 indicates the type I error rates and replicates column 4 of Table 3 (i.e., no event-induced volatility). The rest of the lines of Table 5 indicate the rejection rates for the respective abnormal returns shown in the first column.

[Table 5]

There are three outstanding results. First, at all levels of abnormal returns (positive or negative), ORDIN, which is based on non-standardized returns is materially less powerful than the other test statistics that are based on standardized returns. Second, the nonparametric tests of CUMRANK-Z, CAMPBELL-WASLEY and CUMRANK-T have superior power over the parametric tests of PATELL and BMP in all CAR-windows. Third, the test statistic CAMPBELL-WASLEY seem to loose its power for longer CAR-windows faster than CUMRANK-Z and CUMRANK-T.

\subsubsection{Clustered event days}

In order to investigate the impact of cross-sectional correlation, due to the clustered event days, on the Type I error and power of the tests, we conducted a simulation design where in each simulation round a single event days is randomly selected from the sample period and $n=50$ securities are randomly selected without replacement, such that each sampled security has the same event day. Otherwise the simulation design is similar to that of non-clustered 
event days described in Section 4.

Table 6 reports the Type I error and power results of the tests with clustered event-days. The zero abnormal return line in each panel again indicates the Type I error rates at the 5 percent level under the null hypothesis of no event mean effect. Consistent with earlier results [e.g., Kolari and Pynnonen (2010)], test statistics like ORDIN, PATELL, BMP, and CUMRANK-Z that do not account for cross-correlation due to event day clustering are prone to material over-rejection of the true null hypothesis of no event effect. CAMPBELLWASLEY and CUMRANK-T implicitly account for the cross-correlation, which seems to protect them in a satisfactory manner from the over-rejection symptom. Otherwise, however, a notable distinctions of the power results in Table 6 of these statistics compared to those in Table 5 is that the powers tend to be discernibly lower in the clustered case. This is due to the information loss caused by cross-correlation. The problem is discussed in more detail in Kolari and Pynnonen (2010), however, extreme example may explain the intuition. In the extreme if the returns have cross-sectional correlation equal to one, all the returns are essentially the same. Hence knowing one means knowing all. This implies that additional cross-sectional observations do not add information and the effective sample size is always equal to one no matter how many cross-sectional observations are collected. In the other extreme of independence nothing can be predicted from a single return and thus each return brings along unique information and the effective sample size is the number of observations. Between these extremes the effective sample size adjust accordingly. The simulation results in Table 6 clearly indicate the deflation effect of cross-correlation in the powers of the test statistics ORDIN, PATELL, BMP, and CUMRANK-Z assume that rely on independence and 
hence have high power, which, however, badly misleads because of the strong over-rejection which make them useless in this context.

In summary, the derived test statistic CUMRANK-T as well the CAMPBELL-WASLEY statistic are quite robust to clustered event days. In addition the well established asymptotic properties of CUMRANK-T, its robustness against event-induced volatility, and highly competitive power compared to tests that do not tolerate cross-correlation makes it a recommended robust testing procedure in event studies. In particular it is is the case if the focus is in market efficiency issues.

[Table 6]

\section{Conclusion}

This paper proposed a new test statistic (called CUMRANK-T in the text), which is used for testing (cumulative) abnormal returns. For a fixed estimation period the asymptotic distribution of the test statistic is shown to be Student's $t$-distribution with $T-2$ degrees of freedom, where $T$ is the length of time series. It is shown in the paper that this asymptotic result holds also under certain degree of cross-sectional correlation, which is typically caused by event day clusterings. Simulation results with real returns reveal that with $n=50$ securities the asymptotic distribution performs as a reasonable approximation for the test statistic. Furthermore, consistent with the theoretical derivations the simulations show that the statistic is well specified under the null hypothesis of no event mean effect and is robust 
to event-induced volatility and to cross-correlation (clustered event days) of the returns. Our simulation study also revealed that this test statistic has superior empirical power against the ordinary $t$-test and the popular parametric tests by Patell (1976) and Boehmer, Musumeci and Poulsen (1991). Again, consistent with the theoretical derivations, the simulation results with real returns confirmed that in longer accumulation windows the test statistic tends to reject the null hypothesis closer to the nominal rate than the rank test based approach suggested in Campbell and Wasley (1993). The Campbell and Wasley statistic suffers from a small technical bias in the standard error of the statistic that does not harm the statistic in short period cumulative abnormal returns (CARs) but cause under-rejection of the null hypothesis in longer CARs. This paper fixes the bias and derives the proper asymptotic distribution of the adjusted statistic with a result that leads to the new CUMRANK-T statistic.

\section{References}

Barber, B. M. and Lyon, J. D. (1997): Detecting long-run abnormal returns: The empirical power and specification test statistics, Journal of Financial Economics, 81, 175-213.

Beaver, W. H. (1968): The information content of annual announcements, Journal of Accounting research Supplement, 6, 67-92.

Boehmer, E., Musumeci J., and Poulsen, A. B. (1991): Event-study methodology under conditions of event-induced variance, Journal of Financial Economics, 30, 253-272.

Brown, S. J. and Warner, J. B. (1980): Measuring security price performance, Journal of 
Financial Economics, 8, 205-258.

Brown, S. J. and Warner, J. B. (1985): Using daily stock returns: The case of event studies, Journal of Financial Economics, 14, 3-31.

Campbell, C. J. and Wasley C. E. (1993): Measuring security performance using daily NASDAQ returns, Journal of Financial Economics, 33, 73-92.

Campbell, C. J. and Wasley C. E. (1996): Measuring abnormal trading volume for samples of NYSE/ASE and NASDAQ securities using parametric and non-parametric test statistics, Review of Quantitative Finance and Accounting, 6, 309-326.

Campbell, J. Y., Lo, A. W. and MacKinlay A. C. (1997): The Econometrics of Financial Markets, Princeton, NJ: Princeton University Press.

Charest, G. (1978): Dividend information, stock returns, and market efficiency, Journal of Financial Economics, 6, 265-296.

Corrado, C. J. (1989): A nonparametric test for abnormal security price performance in event studies, Journal of Financial Economics, 23, 385-395.

Corrado, C. J. and Truong, C. (2008). Conducting event studies with Asia-Pasific security market data. Pacific-Basin Finance Journal, 16, 493-521.

Corrado, C. J. and Zivney, T. L. (1992): The specification and power of the sign test in event study hypothesis test using daily stock returns, Journal of Financial and Quantitative Analysis, 27, 465-478. 
Cowan, A. R. (1992): Nonparametric event study tests, Review of Quantitative Finance and Accounting 2, 343-358.

Cowan, A. R. and Sergeant, A. M. A. (1996): Trading frequency and event study test specification, Journal of Banking \& Finance, 20, 1731-1757.

Dechow, P., Sloan R. and Sweeney, A. (1995): Detecting earnings management, Accounting Review, 70, 3-42.

Gibbons, J. D. and Chakraborti, S. (1992):Nonparametric Statistical Inference, Marcel Dekker Inc, New York.

Harrington, S. E. and Shrider, D. G. (2007): All events induce variance: Analyzing abnormal returns when effects vary across firms, Journal of Financial and Quantitative Analysis, 42, 229-256.

Kolari, J. W. and Pynnönen, S. (2010): Event study testing with cross-sectional correlation of abnormal returns, Journal of Financial Research, forthcoming.

Kolari, J. W. and Pynnönen, S. (2010b): Nonparametric Rank Tests for Event Studies. 21st Australasian Finance and Banking Conference 2008 Paper.

SSRN: http://ssrn.com/abstract $=1254022$.

Kothari, S. P., Leone, A. and Wasley C. (2005): Performance-matched discretionary accruals, Journal of Accounting and Economics, 39, 163-197.

Lehmann, E.L. (1999): Elements of Large-Sample Theory, New York, Springer-Verlag. 
Mikkelson, W. H. (1981): Convertible calls and security returns, Journal of Financial Economics, 9, 237-264.

Mann, H. B. and Whitney, D. R. (1947): On a test whether one of two random variables is stochastically larger than the other, Annals of Statistics, 18, 50-60.

Patell, J. A. (1976): Corporate forecasts of earnings per share and stock price behavior: Empirical test, Journal of Accounting Research, 14, 246-276.

Penman, S. H. (1982): Insider trading and the dissemination of firms forecast information. Journal of Business, 55, 479-503.

Peterson, P. P. (1989): Event studies: A review of issues and methodology. Quaterly Journal of Business and Economics, 28, 36-66.

Pynnönen, S. (2010). The joint distribution of an arbitrary linear transformation of internally studentized least squares residuals of a linear regression. Working Paper, University of Vaasa.

Rosenstein, S. and Wyatt, J. G. (1990): Outside directors, board independence, and shareholders wealth, Journal of Financial Economics, 26, 175-191.

Wilcoxon, F. (1945): Individual comparisons by ranking methods, Biometrics Bulletin, 1, $80-83$. 


\section{APPENDIX: Asymptotic distributions of rank tests}

We utilize the following Lemmas in the proofs of Theorem 3 and Theorem 4 . Proofs of these Lemmas can be obtained as special cases from Pynnönen (2010).

\section{Lemma 1 Define}

$$
\boldsymbol{x}=\mathrm{Q} \boldsymbol{y},
$$

where $\mathbf{Q}$ is a $T \times T$ idempotent matrix of rank $r \leq T$ and $\boldsymbol{y}=\left(y_{1}, \ldots, y_{T}\right)^{\prime}$ is a vector of independent $N(0,1)$ random variables, such that $\boldsymbol{y} \sim N(\mathbf{0}, \mathbf{I})$, where $\mathbf{I}$ is a $T \times T$ identity matrix. Furthermore, let $\boldsymbol{m}$ be a $T$ component column vector of real numbers such that $\boldsymbol{m}^{\prime} \mathrm{Q} \boldsymbol{m}>0$. Then

$$
z_{m}=\frac{\boldsymbol{m}^{\prime} \boldsymbol{x} / \sqrt{\boldsymbol{m}^{\prime} \mathbf{Q} \boldsymbol{m}}}{\sqrt{\boldsymbol{x}^{\prime} \boldsymbol{x} / r}}
$$

has the distribution with density function

$$
f_{z_{m}}(z)=\frac{\Gamma(r / 2)}{\Gamma[(r-1) / 2] \sqrt{r \pi}}\left(1-\frac{z^{2}}{r}\right)^{\frac{1}{2}(r-1)-1},
$$

when $|z|<\sqrt{r}$, and zero otherwise, where $\Gamma(\cdot)$ is the gamma function.

Lemma 2 Under the assumptions of Lemma 1

$$
t_{m}=z_{m} \sqrt{\frac{r-1}{r-z_{m}^{2}}}
$$

is distributed as the Studen t-distribution with $r-1$ degrees of freedom.

Proof (Theorem 3): The proof of the theorem is a adapted from Kolari and Pynnonen (2010b). In order to derive the asymptotic distribution of the adjusted CAMPBELL- 
WASLEY statistic, $Z_{2}^{\prime}$, defined in equation (41), we collect the deviations of cross-sectional average abnormal (scaled) ranks $K_{i t}$ defined in (14) from their expected values, $1 / 2$, to a column vector $\boldsymbol{d}_{i}=\left(d_{i, 1}, d_{i, 2}, \ldots, d_{i, T}\right)^{\prime}$, where $d_{i, t}=K_{i, T_{0}+t}-1 / 2, t=1, \ldots T=T_{2}-T_{0}$ and the prime denotes transpose and $i=1, \ldots, n$ with $n$ the number of series. Then by assumption the random vectors $\boldsymbol{d}_{i}$ s are independent and, by Proposition 1, identically distributed random vectors with zero means and identical equicorrelation covariance matrices such that

$$
\begin{aligned}
E\left[\boldsymbol{d}_{i}\right] & =\mathbf{0} \\
\operatorname{cov}\left[\boldsymbol{d}_{i}\right] & =\frac{T-1}{12(T+1)}\left((1-\varrho) \mathbf{I}+\varrho \boldsymbol{\iota}^{\prime}\right),
\end{aligned}
$$

for all $i=i, \ldots, n$, where $\iota$ is a vector of $T$ ones, $\mathbf{I}$ is a $T \times T$ identity matrix, and

$$
\varrho=-\frac{1}{T-1}
$$

is the serial correlation of the ranks. Thus, the covariance matrix (64) becomes

$$
\Sigma=\operatorname{cov}\left[\boldsymbol{d}_{i}\right]=\frac{T}{12(T+1)}\left(\mathbf{I}-\frac{1}{T} \boldsymbol{\iota \iota}^{\prime}\right)
$$

It should be noted that the matrix $\mathbf{I}-T^{-1} \boldsymbol{\iota} \boldsymbol{\iota}^{\prime}$ is an idempotent matrix of rank $T-1$, which implies that $\Sigma$ is singular.

However, because $\boldsymbol{d}_{i}$ s are independent with zero means and finite covariance matrices (66), the central limit theorem applies such that

$$
\sqrt{n} \overline{\boldsymbol{d}} \stackrel{d}{\rightarrow}\left(\frac{T}{12(T+1)}\right)^{\frac{1}{2}} \boldsymbol{x}
$$

as $n \rightarrow \infty$, where

$$
\boldsymbol{x} \sim N(\mathbf{0}, \mathbf{Q})
$$


with the (idempotent) singular covariance matrix

$$
\mathbf{Q}=\mathbf{I}-\frac{1}{T} \iota \iota^{\prime},
$$

and in $(67), \overline{\boldsymbol{d}}=\left(\bar{d}_{1}, \ldots \bar{d}_{T}\right)^{\prime}$ with

$$
\bar{d}_{t}=\frac{1}{n} \sum_{i=1}^{n} d_{i t}=\frac{1}{n} \sum_{i=1}^{n}\left(K_{i, T_{0}+t}-\frac{1}{2}\right)
$$

the time $t$ cross-sectional mean of the deviations $K_{i, T_{0}+t}-1 / 2$ of the scaled ranks, $t=1, \ldots, T$. Note that the sum of $d_{i, t}$ over the time index $t$ is zero for all $i=1, \ldots, n$, i.e., $\iota^{\prime} \boldsymbol{d}_{i}=0$ for all $i=1, \ldots, n$, which implies that $\iota^{\prime} \overline{\boldsymbol{d}}=0$.

Let $\boldsymbol{\iota}_{\tau_{1}, \tau_{2}}$ be a column vector of length $T$ with ones in positions in the event window from $\tau_{1}$ to $\tau_{2}$ and zeros elsewhere. Then we can write $Z_{2}^{\prime}$ defined in equation (41) as

$$
Z_{2}^{\prime}=\frac{\boldsymbol{\iota}_{\tau_{1}, \tau_{2}}^{\prime} \overline{\boldsymbol{d}}}{\sqrt{\overline{\boldsymbol{d}}^{\prime} \overline{\boldsymbol{d}}}} \sqrt{\frac{T(T-1)}{\tau(T-\tau)}}=\frac{\boldsymbol{\iota}_{\tau_{1}, \tau_{2}}^{\prime} \overline{\boldsymbol{d}} / \sqrt{\tau(T-\tau) / T}}{\sqrt{\overline{\boldsymbol{d}}^{\prime} \overline{\boldsymbol{d}} /(T-1)}} .
$$

Defining in Lemma 1

$$
\boldsymbol{m}=\boldsymbol{\iota}_{\tau_{1}, \tau_{2}}
$$

and

$$
\mathbf{Q}=\mathbf{I}-\frac{1}{T} \iota \iota^{\prime},
$$

we obtain

$$
\boldsymbol{m}^{\prime} \mathbf{Q} \boldsymbol{m}=\frac{\tau(T-\tau)}{T}
$$

such that the ratio $z_{m}$ in $(60)$ becomes

$$
Z=\frac{\boldsymbol{\iota}_{\tau_{1}, \tau_{2}}^{\prime} \boldsymbol{x} / \sqrt{\tau(T-1) / T}}{\sqrt{\boldsymbol{x}^{\prime} \boldsymbol{x} /(T-1)}},
$$


the distribution of which, after arranging term, has the density function,

$$
f_{Z}(z)=\frac{\Gamma[(T-1) / 2]}{\Gamma[(T-2) / 2] \sqrt{(T-1) \pi}}\left(1-\frac{z^{2}}{T-1}\right)^{\frac{1}{2}(T-3)}
$$

for $|z|<\sqrt{T-1}$ and zero elsewhere.

Because of the convergence result in (67) and that the function

$$
h(\overline{\boldsymbol{d}})=\frac{\iota_{\tau_{1}, \tau_{2}}^{\prime} \overline{\boldsymbol{d}} / \sqrt{\tau(T-\tau) / T}}{\sqrt{\overline{\boldsymbol{d}}^{\prime} \overline{\boldsymbol{d}} /(T-1)}}
$$

is continuous, the continuous mapping theorem implies $h(\overline{\boldsymbol{d}}) \stackrel{d}{\rightarrow} h(\boldsymbol{x})$. That is,

$$
Z_{2}^{\prime}=\frac{\boldsymbol{\iota}_{\tau_{1}, \tau_{2}}^{\prime} \overline{\boldsymbol{d}} / \sqrt{\tau(T-\tau) / T}}{\sqrt{\overline{\boldsymbol{d}}^{\prime} \overline{\boldsymbol{d}} /(T-1)}} \stackrel{d}{\rightarrow} \frac{\boldsymbol{\iota}_{\tau_{1}, \tau_{2}}^{\prime} \boldsymbol{x} / \sqrt{\tau(T-1) / T}}{\sqrt{\boldsymbol{x}^{\prime} \boldsymbol{x} /(T-1)}}=Z,
$$

which implies that the density function of the limiting distribution of $Z_{2}^{\prime}$ for fixed $T$, as $n \rightarrow \infty$, is of the form defined in equation (72), completing the proof of Theorem 3 .

Proof (Theorem 4): By the proof of Theorem 3, $Z_{2}^{\prime} \stackrel{d}{\rightarrow} Z$, where $Z$ is defined in equation (71) with $r=T-1$. Again because the function $g(z)=z \sqrt{(T-2) /\left(T-1-z^{2}\right)}$ is continuous, for $|z|<\sqrt{T-1}$, the continuous mapping theorem implies $t_{\text {cumrank }}=g\left(Z_{2}^{\prime}\right) \stackrel{d}{\rightarrow} g(Z)$. That is,

$$
t_{\text {cumrank }} \stackrel{d}{\rightarrow} Z \sqrt{\frac{T-2}{T-1-Z^{2}}}
$$

where the distribution of the right hand side expression is by Lemma 2 the $t$-distribution with $T-2$ degrees of freedom, completing the proof of Theorem 4 . 
Table 1: Sample statistics in event tests for 1,000 random portfolios on $n=50$ securities belonging to S\&P400-, S\&P500- and S\&P600-indexes.

\begin{tabular}{|c|c|c|c|c|c|c|c|}
\hline \multicolumn{8}{|l|}{ Test statistics } \\
\hline Panel A: $\operatorname{AR}(0)$ & Mean & Med. & Std. & Skew. & Kurt. & Min. & Max. \\
\hline Abnormal return, $\%$ & 0.004 & -0.008 & 0.413 & -0.082 & 1.018 & -1.688 & 1.641 \\
\hline ORDIN & 0.008 & -0.019 & 1.053 & -0.079 & 0.701 & -3.878 & 3.694 \\
\hline PATELL & -0.024 & -0.036 & 1.113 & -0.193 & 1.170 & -6.178 & 3.837 \\
\hline BMP & -0.013 & -0.032 & 1.000 & -0.014 & 0.144 & -3.999 & 3.774 \\
\hline CUMRANK-Z & 0.001 & -0.021 & 0.979 & 0.046 & 0.150 & -3.809 & 3.578 \\
\hline CAMPBELL-WASLEY & 0.000 & -0.020 & 0.956 & 0.039 & 0.038 & -3.479 & 3.323 \\
\hline CUMRANK-T & 0.000 & -0.020 & 0.959 & 0.039 & 0.087 & -3.556 & 3.390 \\
\hline Panel B: CAR $(-1,+1)$ & Mean & Med. & Std. & Skew. & Kurt. & Min. & Max. \\
\hline $\operatorname{CAR}(-1,+1), \%$ & -0.010 & -0.029 & 0.671 & -0.019 & 0.146 & -2.288 & 2.096 \\
\hline ORDIN & -0.018 & -0.040 & 0.988 & -0.028 & 0.306 & -3.759 & 3.329 \\
\hline PATELL & $-0.067^{b}$ & -0.085 & 1.077 & 0.133 & 0.113 & -3.380 & 4.059 \\
\hline BMP & $-0.054^{a}$ & -0.088 & 1.023 & 0.160 & 0.083 & -3.208 & 3.856 \\
\hline CUMRANK-Z & -0.009 & 0.008 & 0.987 & 0.084 & -0.018 & -2.882 & 3.166 \\
\hline CAMPBELL-WASLEY & -0.010 & 0.007 & 0.961 & 0.067 & -0.054 & -2.758 & 3.128 \\
\hline CUMRANK-T & -0.010 & 0.007 & 0.968 & 0.070 & -0.014 & -2.806 & 3.195 \\
\hline Panel C: CAR $(-5,+5)$ & Mean & Med. & Std. & Skew. & Kurt. & Min. & Max. \\
\hline $\operatorname{CAR}(-5,+5), \%$ & -0.076 & -0.027 & 1.269 & -0.114 & 0.346 & -5.178 & 4.455 \\
\hline ORDIN & $-0.060^{b}$ & -0.020 & 0.959 & -0.183 & 0.433 & -3.977 & 3.441 \\
\hline PATELL & $-0.132^{c}$ & -0.108 & 1.107 & -0.034 & 0.363 & -4.005 & 3.992 \\
\hline BMP & $-0.113^{c}$ & -0.117 & 1.036 & 0.088 & 0.157 & -3.417 & 3.603 \\
\hline CUMRANK-Z & $-0.067^{c}$ & -0.094 & 0.958 & 0.172 & 0.149 & -3.037 & 3.338 \\
\hline CAMPBELL-WASLEY & $-0.067^{c}$ & -0.092 & 0.921 & 0.145 & 0.119 & -2.911 & 3.167 \\
\hline CUMRANK-T & $-0.069^{c}$ & -0.094 & 0.942 & 0.148 & 0.168 & -3.014 & 3.290 \\
\hline & & & & & & Cor & ued) \\
\hline
\end{tabular}


Table 1, continued

\begin{tabular}{|c|c|c|c|c|c|c|c|}
\hline \multicolumn{8}{|l|}{ Test statistics } \\
\hline Panel D: CAR $(-10,+10)$ & Mean & Med. & Std. & Skew. & Kurt. & Min. & Max. \\
\hline $\operatorname{CAR}(-10,+10), \%$ & -0.056 & -0.029 & 1.800 & -0.136 & 0.018 & -5.442 & 4.845 \\
\hline ORDIN & -0.038 & -0.015 & 0.967 & -0.225 & 0.149 & -3.332 & 2.749 \\
\hline PATELL & $-0.130^{c}$ & -0.108 & 1.105 & -0.287 & 0.852 & -5.208 & 4.129 \\
\hline BMP & $-0.100^{c}$ & -0.117 & 1.042 & 0.011 & 0.033 & -3.092 & 3.759 \\
\hline CUMRANK-Z & $-0.048^{a}$ & -0.046 & 0.923 & 0.005 & -0.028 & -2.873 & 3.078 \\
\hline CAMPBELL-WASLEY & $-0.048^{a}$ & -0.042 & 0.866 & 0.011 & -0.065 & -2.447 & 3.051 \\
\hline CUMRANK-T & $-0.050^{a}$ & -0.043 & 0.904 & 0.011 & -0.033 & -2.575 & 3.233 \\
\hline
\end{tabular}

This table reports sample statistics from 1,000 simulations for the event day abnormal returns and for the cumulative abnormal returns: $\operatorname{CAR}(-1,+1), \operatorname{CAR}(-5,+5)$, and $\operatorname{CAR}(-10,+10)$. It also reports the sample statistics for the test statistics ORDIN [Eq. (54), PATELL [Eq. (56)], BMP [Eq. (57)], CUMRANK-Z [Eq. (32)], CAMPBELL-WASLEY [Eq. (36)] and CUMRANK-T [Eq. (42)] for $\operatorname{AR}(0), \operatorname{CAR}(-1,+1), \operatorname{CAR}(-5,+5)$ and $\operatorname{CAR}(-10,+10)$. The data is based on 1,000 simulations for portfolios of size $n=50$ securities with an estimation period of 239 days and event period of 21 days. The event day is denoted as $t=0$. Cumulative abnormal returns $\operatorname{CAR}(-d,+d)$ with $d=0,1,5$ and 10 are computed around the event day. The data consist of securities belonging to S\&P400-, S\&P500- and S\&P600-indexes from the period July, 1991 to October, 2009. The returns are calculated with the help of the market model presented in equation (51). Superscripts $a, b$ and $c$ correspond to the significance levels $0.10,0.05$ and 0.01 . 


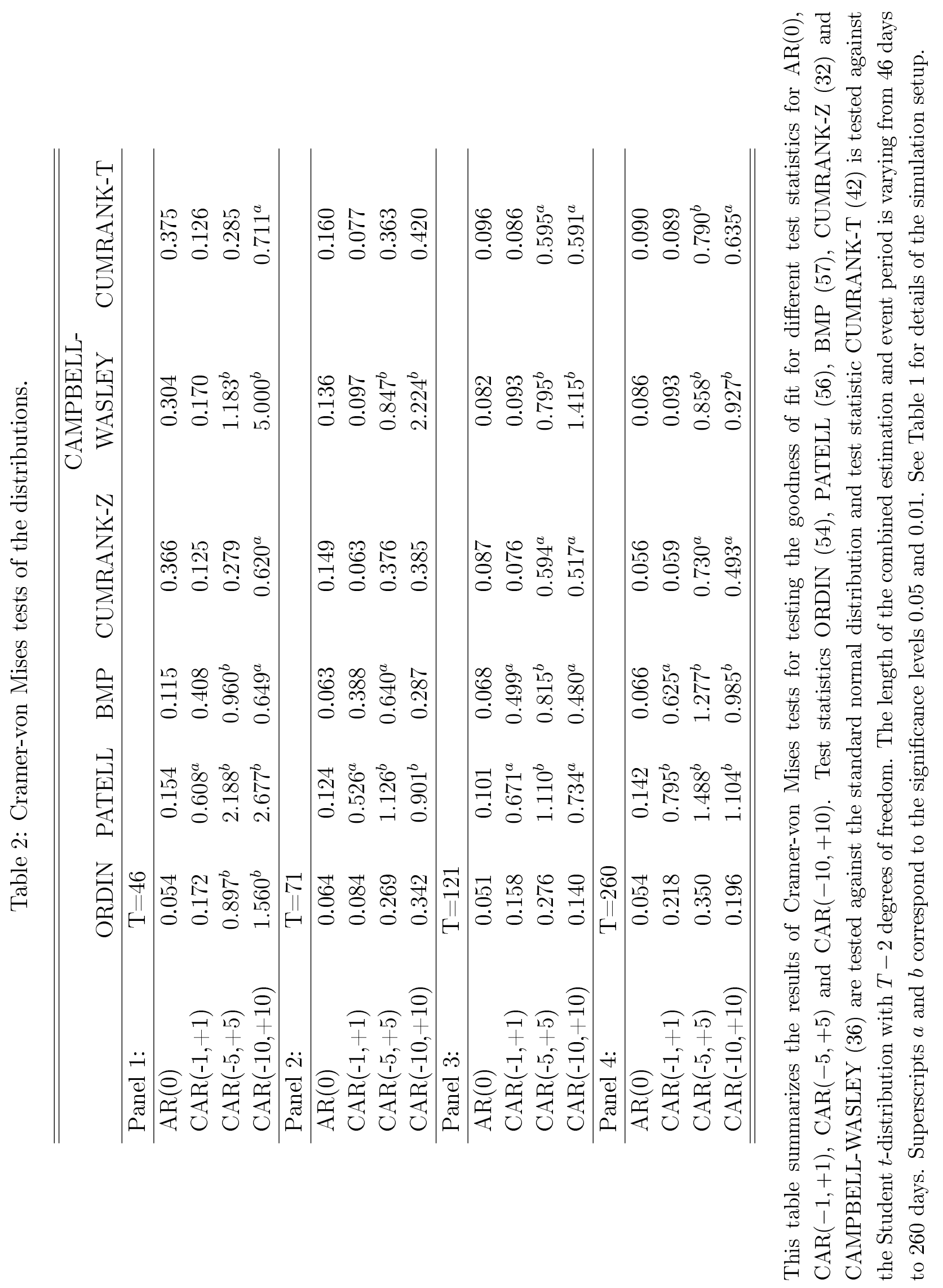




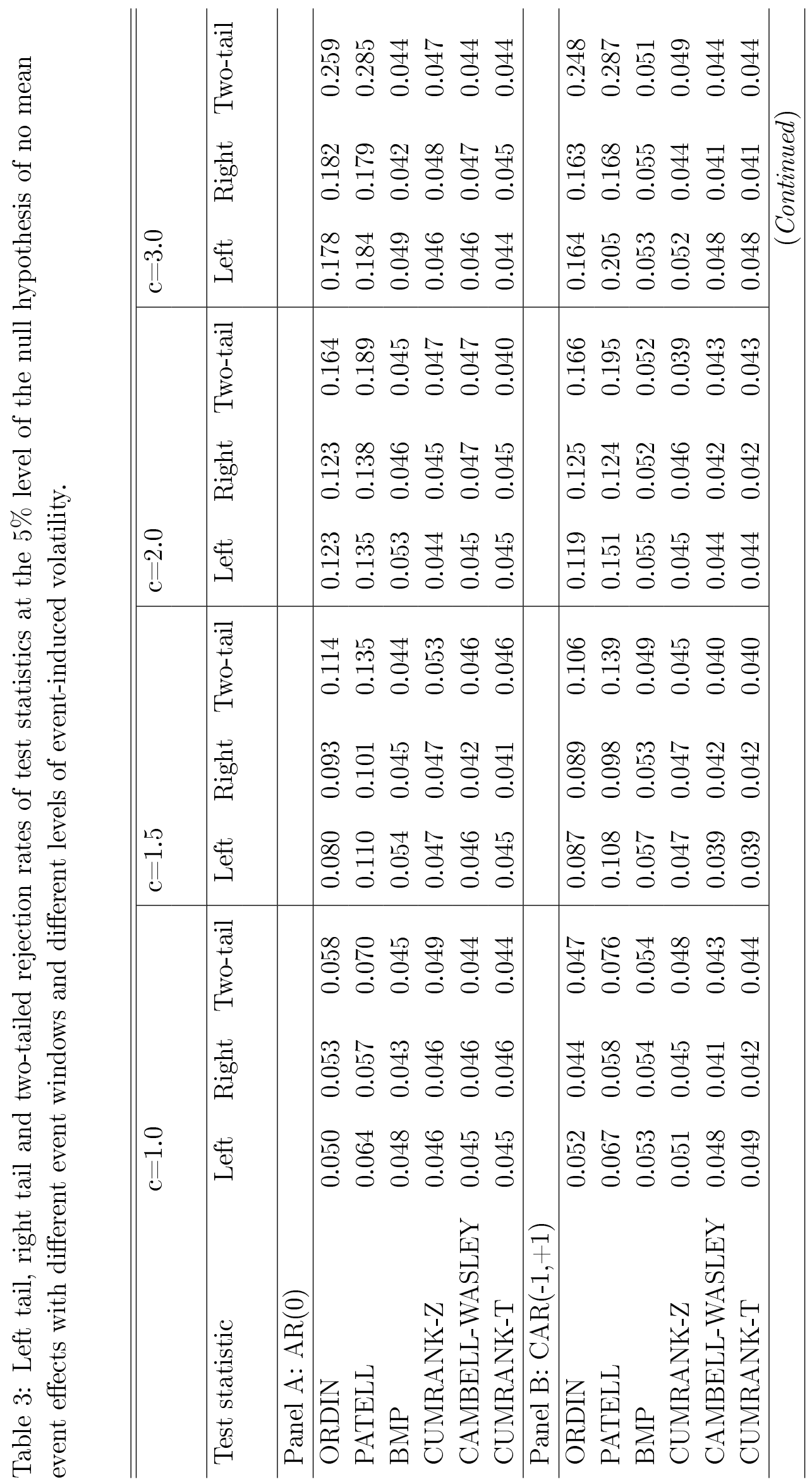




\begin{tabular}{|c|c|c|c|c|c|c|}
\hline$\stackrel{0}{\stackrel{0}{0}}$ & 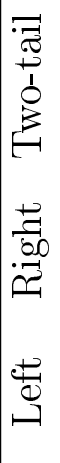 & & 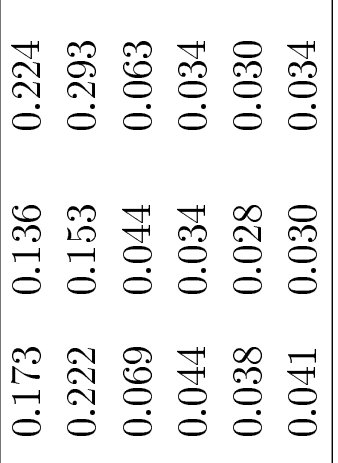 & & 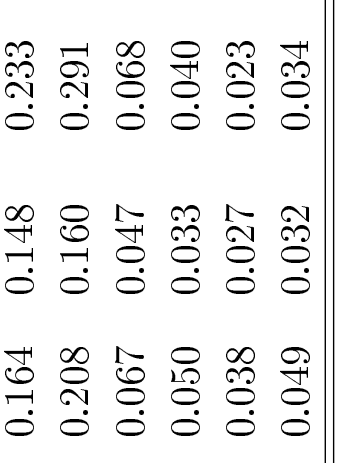 & 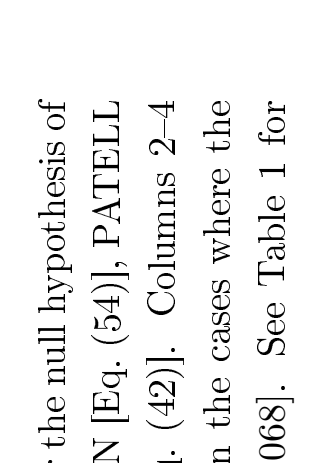 \\
\hline $\begin{array}{l}0 \\
i \\
i \\
i\end{array}$ & 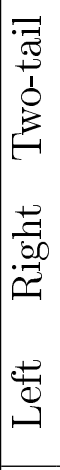 & & 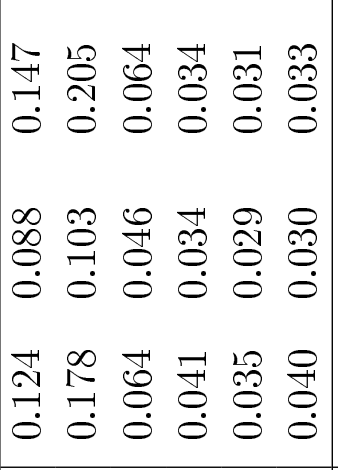 & & 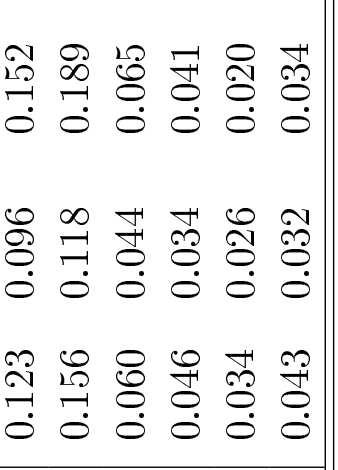 & 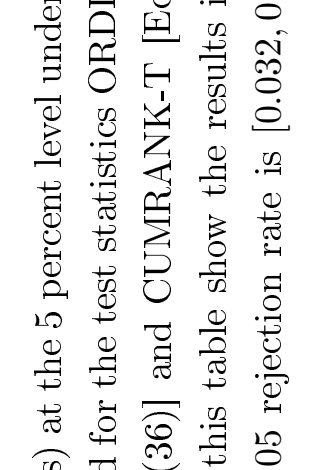 \\
\hline ְִ & 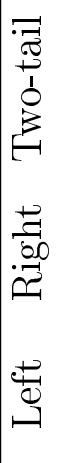 & & 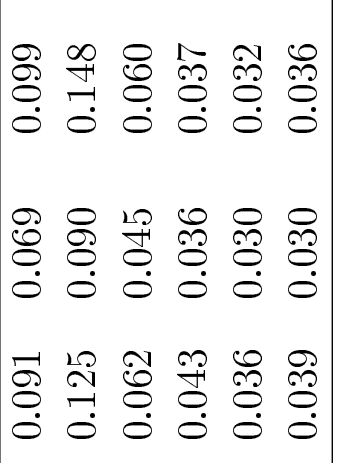 & & 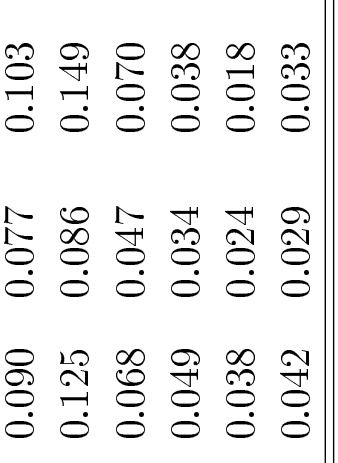 & 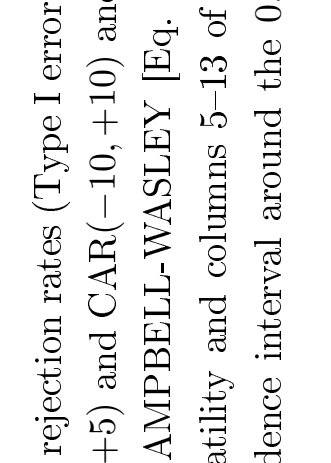 \\
\hline$\frac{0}{\pi}$ & 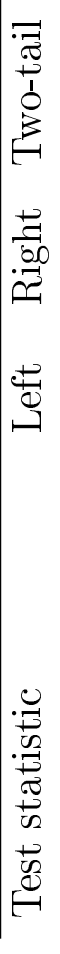 & 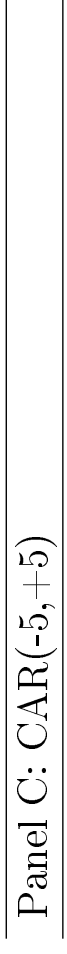 & 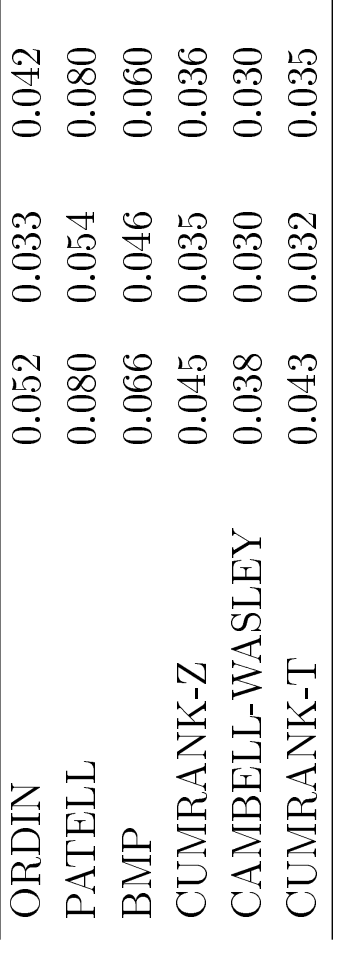 & 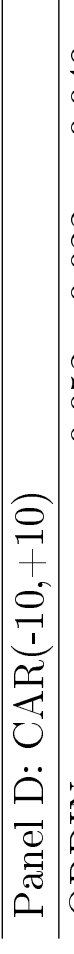 & 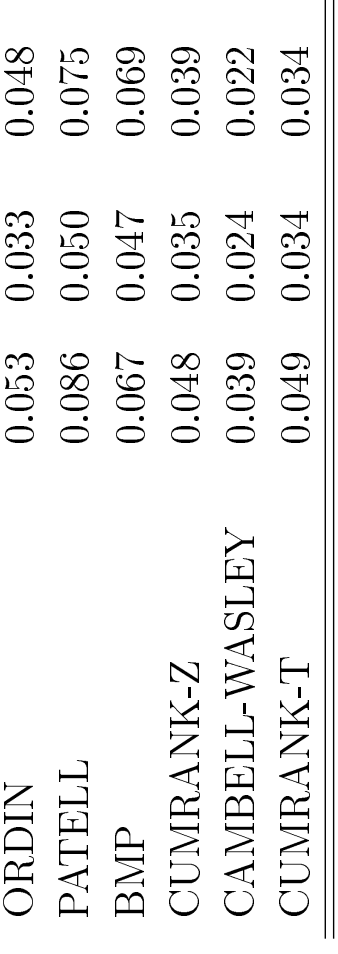 & 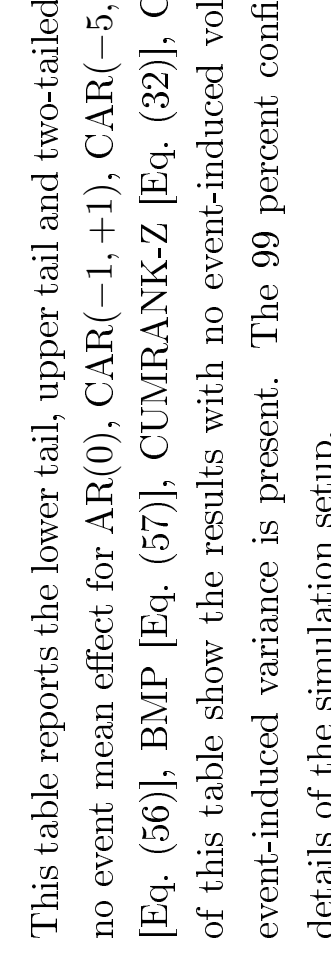 \\
\hline
\end{tabular}




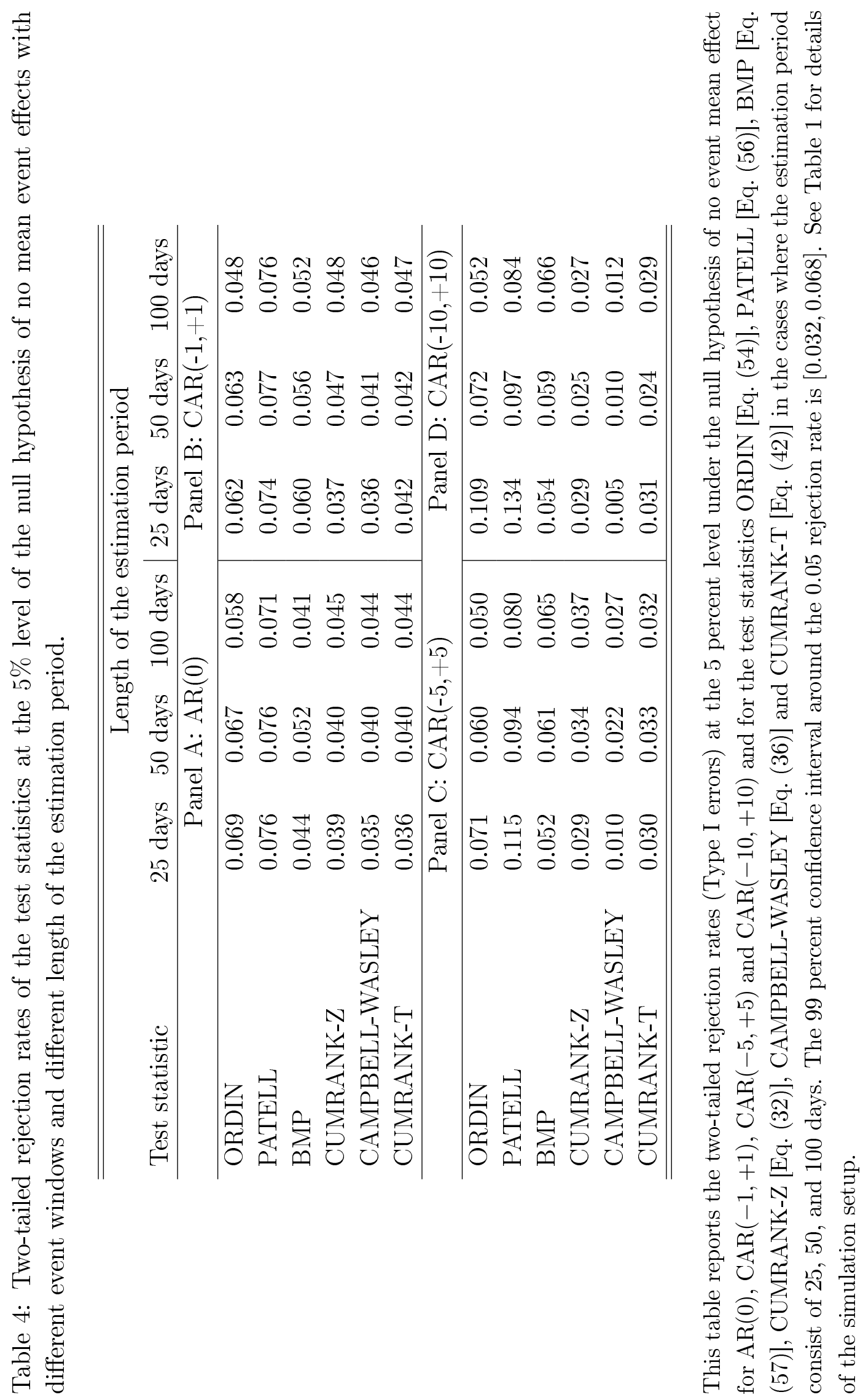


Table 5: Non-clustered event days: Powers of selected test statistics in two-tailed testing at the $5 \%$ significance from 1,000 random portfolios of $n=50$ securities with evenly distributed abnormal return over the time period accumulated to the CAR when the event days are nonclustered.

\begin{tabular}{lcccccc}
\hline \hline \multicolumn{7}{c}{ Panel A: AR(0) } \\
\hline AR & ORDIN & PATELL & BMP & RANK-Z & WASLEY & RANK-T \\
\hline-3.0 & 1.000 & 1.000 & 1.000 & 1.000 & 1.000 & 1.000 \\
-2.0 & 0.996 & 1.000 & 0.999 & 1.000 & 1.000 & 1.000 \\
-1.0 & 0.719 & 0.958 & 0.910 & 0.963 & 0.958 & 0.959 \\
\pm 0.0 & 0.058 & 0.070 & 0.045 & 0.049 & 0.044 & 0.044 \\
+1.0 & 0.722 & 0.942 & 0.899 & 0.977 & 0.971 & 0.971 \\
+2.0 & 0.994 & 0.999 & 0.996 & 0.999 & 0.999 & 0.999 \\
+3.0 & 1.000 & 1.000 & 0.999 & 1.000 & 1.000 & 1.000 \\
\hline \multicolumn{7}{c}{ Panel B: CAR(-1,+1) } \\
AR & ORDIN & PATELL & BMP & RANK-Z & WASLEY & RANK-T \\
\hline-3.0 & 0.994 & 1.000 & 0.999 & 1.000 & 1.000 & 1.000 \\
-2.0 & 0.833 & 0.984 & 0.966 & 0.996 & 0.993 & 0.995 \\
-1.0 & 0.305 & 0.587 & 0.566 & 0.685 & 0.662 & 0.671 \\
\pm 0.0 & 0.047 & 0.076 & 0.054 & 0.048 & 0.043 & 0.044 \\
+1.0 & 0.292 & 0.528 & 0.508 & 0.673 & 0.643 & 0.649 \\
+2.0 & 0.836 & 0.958 & 0.983 & 0.995 & 0.993 & 0.993 \\
+3.0 & 0.987 & 1.000 & 0.999 & 1.000 & 1.000 & 1.000 \\
\hline \hline
\end{tabular}


Table 5 Continued.

\begin{tabular}{|c|c|c|c|c|c|c|}
\hline \multicolumn{7}{|c|}{ Panel C: CAR $(-5,+5)$} \\
\hline $\mathrm{AR}$ & ORDIN & PATELL & BMP & $\begin{array}{c}\text { CUM- } \\
\text { RANK-Z }\end{array}$ & $\begin{array}{c}\text { CAMBELL- } \\
\text { WASLEY }\end{array}$ & $\begin{array}{c}\text { CUM- } \\
\text { RANK-T }\end{array}$ \\
\hline-3.0 & 0.625 & 0.910 & 0.887 & 0.978 & 0.968 & 0.970 \\
\hline-2.0 & 0.320 & 0.612 & 0.610 & 0.740 & 0.717 & 0.733 \\
\hline-1.0 & 0.120 & 0.242 & 0.239 & 0.283 & 0.244 & 0.266 \\
\hline \pm 0.0 & 0.042 & 0.080 & 0.060 & 0.036 & 0.030 & 0.035 \\
\hline+1.0 & 0.083 & 0.179 & 0.169 & 0.227 & 0.198 & 0.209 \\
\hline+2.0 & 0.308 & 0.528 & 0.534 & 0.689 & 0.666 & 0.684 \\
\hline+3.0 & 0.610 & 0.860 & 0.836 & 0.966 & 0.963 & 0.964 \\
\hline \multicolumn{7}{|c|}{ Panel D: CAR $(-10,+10)$} \\
\hline $\mathrm{AR}$ & ORDIN & PATELL & BMP & $\begin{array}{c}\text { CUM- } \\
\text { RANK-Z }\end{array}$ & $\begin{array}{c}\text { CAMBELL- } \\
\text { WASLEY }\end{array}$ & $\begin{array}{c}\text { CUM- } \\
\text { RANK-T }\end{array}$ \\
\hline-3.0 & 0.344 & 0.665 & 0.653 & 0.805 & 0.766 & 0.793 \\
\hline-2.0 & 0.184 & 0.379 & 0.375 & 0.472 & 0.419 & 0.454 \\
\hline-1.0 & 0.091 & 0.167 & 0.157 & 0.151 & 0.129 & 0.145 \\
\hline \pm 0.0 & 0.048 & 0.075 & 0.069 & 0.039 & 0.022 & 0.034 \\
\hline+1.0 & 0.069 & 0.125 & 0.118 & 0.118 & 0.102 & 0.111 \\
\hline+2.0 & 0.162 & 0.313 & 0.320 & 0.435 & 0.365 & 0.420 \\
\hline+3.0 & 0.338 & 0.595 & 0.578 & 0.767 & 0.709 & 0.752 \\
\hline
\end{tabular}

This table reports the power results of the test statistics ORDIN [Eq. (54)], PATELL [Eq. (56)], BMP [Eq. (57)], CUMRANK-Z [Eq. (32)], CAMPBELL-WASLEY [Eq. (36)] and CUMRANK-T [Eq. (42)] for two-tailed tests for $\operatorname{AR}(0), \operatorname{CAR}(-1,+1), \operatorname{CAR}(-5,+5)$ and $\operatorname{CAR}(-10,+10)$. The zero abnormal return line in each panel of this table indicates the type I error rates and replicates column 4 of Table 3 (i.e., no event-induced volatility). The rest of the lines indicate the rejection rates for the respective abnormal return shown in the first column. The abnormal return is evenly distributed across the days over which the CAR is accumulated. For example, in AR(0) the abnormal return is assigned to the event days while in $\operatorname{CAR}(-5,+5)$ the abnormal return is divided by 11 and one 11th of the abnormal return is added to each day's return within the 11 day window. General details of the simulation setup are given in Table 1. 
Table 6: Clustered event days: Powers of selected test statistics in two-tailed testing at the $5 \%$ significance from 1,000 random portfolios of $n=50$ securities with evenly distributed abnormal return over the time period accumulated to the CAR when the event days are clustered.

\begin{tabular}{|c|c|c|c|c|c|c|}
\hline \multicolumn{7}{|c|}{ Panel A: $\operatorname{AR}(0)$} \\
\hline $\mathrm{AR}$ & ORDIN & PATELL & $\mathrm{BMP}$ & $\begin{array}{c}\text { CUM- } \\
\text { RANK-Z }\end{array}$ & $\begin{array}{c}\text { CAMBELL- } \\
\text { WASLEY }\end{array}$ & $\begin{array}{c}\text { CUM- } \\
\text { RANK-T }\end{array}$ \\
\hline-3.0 & 0.995 & 0.998 & 0.996 & 0.998 & 0.990 & 0.990 \\
\hline-2.0 & 0.968 & 0.988 & 0.982 & 0.984 & 0.956 & 0.956 \\
\hline-1.0 & 0.692 & 0.858 & 0.844 & 0.886 & 0.726 & 0.726 \\
\hline \pm 0.0 & 0.177 & 0.203 & 0.216 & 0.241 & 0.055 & 0.055 \\
\hline+1.0 & 0.690 & 0.838 & 0.828 & 0.874 & 0.714 & 0.715 \\
\hline+2.0 & 0.965 & 0.989 & 0.980 & 0.990 & 0.961 & 0.962 \\
\hline+3.0 & 0.999 & 0.999 & 0.996 & 0.999 & 0.992 & 0.992 \\
\hline \multicolumn{7}{|c|}{ Panel B: CAR $(-1,+1)$} \\
\hline $\mathrm{AR}$ & ORDIN & PATELL & $\mathrm{BMP}$ & $\begin{array}{c}\text { CUM- } \\
\text { RANK-Z }\end{array}$ & $\begin{array}{c}\text { CAMBELL- } \\
\text { WASLEY }\end{array}$ & $\begin{array}{c}\text { CUM- } \\
\text { RANK-T }\end{array}$ \\
\hline-3.0 & 0.928 & 0.976 & 0.956 & 0.976 & 0.939 & 0.940 \\
\hline-2.0 & 0.752 & 0.895 & 0.881 & 0.922 & 0.809 & 0.810 \\
\hline-1.0 & 0.395 & 0.556 & 0.569 & 0.653 & 0.389 & 0.395 \\
\hline \pm 0.0 & 0.202 & 0.244 & 0.258 & 0.255 & 0.073 & 0.073 \\
\hline+1.0 & 0.415 & 0.572 & 0.580 & 0.655 & 0.403 & 0.406 \\
\hline+2.0 & 0.777 & 0.893 & 0.882 & 0.932 & 0.819 & 0.822 \\
\hline+3.0 & 0.950 & 0.981 & 0.967 & 0.982 & 0.955 & 0.955 \\
\hline
\end{tabular}


Table 6 continued.

\begin{tabular}{ccccccc}
\hline \hline \multicolumn{7}{c}{ Panel C: CAR $(-5,+5)$} \\
\hline AR & ORDIN & PATELL & BMP & RANK-Z & WASLEY & RANK-T \\
\hline-3.0 & 0.586 & 0.773 & 0.774 & 0.850 & 0.673 & 0.686 \\
-2.0 & 0.404 & 0.551 & 0.574 & 0.667 & 0.407 & 0.416 \\
-1.0 & 0.243 & 0.320 & 0.355 & 0.376 & 0.144 & 0.154 \\
\pm 0.0 & 0.197 & 0.221 & 0.247 & 0.217 & 0.052 & 0.056 \\
+1.0 & 0.276 & 0.349 & 0.360 & 0.395 & 0.150 & 0.155 \\
+2.0 & 0.448 & 0.580 & 0.606 & 0.707 & 0.411 & 0.4322 \\
+3.0 & 0.645 & 0.795 & 0.796 & 0.885 & 0.676 & 0.690 \\
\hline \multicolumn{7}{c}{ Panel D: CAR(-10,+10) } \\
AR & ORDIN & PATELL & BMP & RANK-Z & WASLEY & RANK-T \\
\hline-3.0 & 0.435 & 0.572 & 0.625 & 0.713 & 0.449 & 0.484 \\
-2.0 & 0.326 & 0.442 & 0.462 & 0.528 & 0.248 & 0.273 \\
-1.0 & 0.247 & 0.296 & 0.319 & 0.337 & 0.117 & 0.126 \\
\pm 0.0 & 0.206 & 0.239 & 0.249 & 0.245 & 0.065 & 0.076 \\
+1.0 & 0.237 & 0.288 & 0.316 & 0.328 & 0.095 & 0.111 \\
+2.0 & 0.337 & 0.450 & 0.474 & 0.523 & 0.211 & 0.239 \\
+3.0 & 0.457 & 0.603 & 0.618 & 0.715 & 0.412 & 0.451 \\
\hline \hline
\end{tabular}

This table reports the power results of the test statistics ORDIN [Eq. (54)], PATELL [Eq. (56)], BMP [Eq. (57)], CUMRANK-Z [Eq. (32)], CAMPBELL-WASLEY [Eq. (36)], and CUMRANK-T [Eq. (42)] for two-tailed tests for $\operatorname{AR}(0), \operatorname{CAR}(-1,+1), \operatorname{CAR}(-5,+5)$ and $\operatorname{CAR}(-10,+10)$ in the case where the event days are clustered. The zero abnormal return line in each panel of this table indicates the type I error rates. The rest of the lines of this table indicate the rejection rates for the respective abnormal returns shown in the first column. The abnormal return is evenly distributed across the days over which the CAR is accumulated. For example, in $\operatorname{AR}(0)$ the abnormal return is assigned to the event days while in $\operatorname{CAR}(-5,+5)$ the abnormal return is divided by 11 and one 11 th of the abnormal return is added to each day's return within the 11 day window. General details of the simulation setup are given in Table 1 . With the clustered event days in each simulation round first a single event day is randomly selected which is the same for each of the $n=50$ securities sampled without replacement in the next step. 


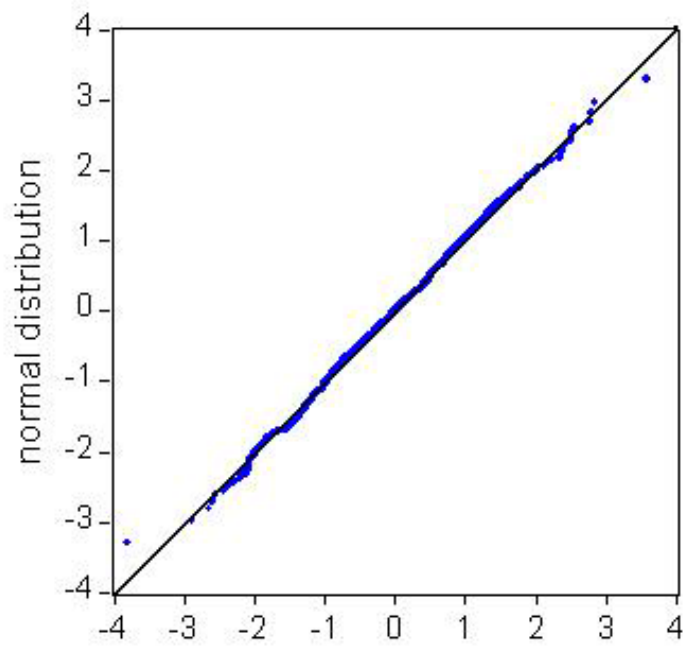

Empirical quantile CUMRANK-Z AR( 0$)$

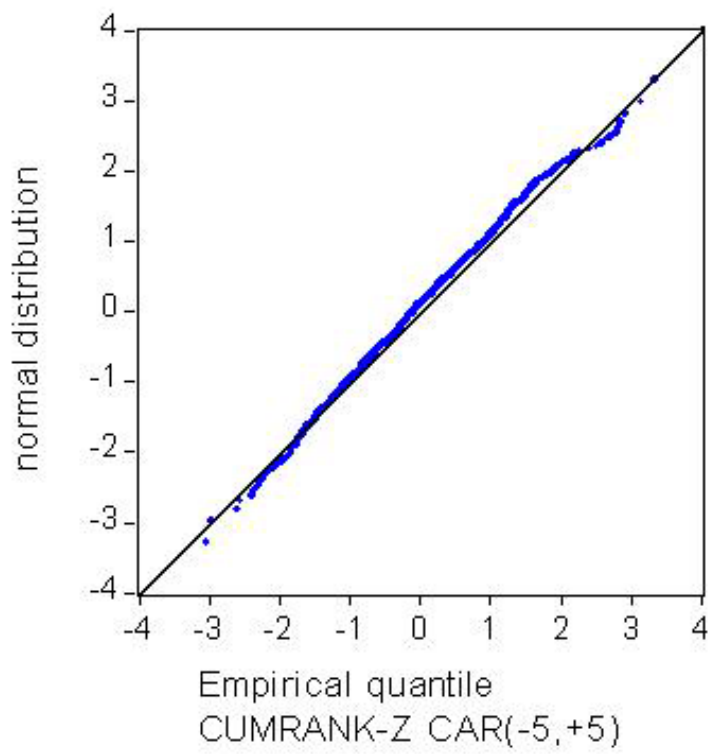

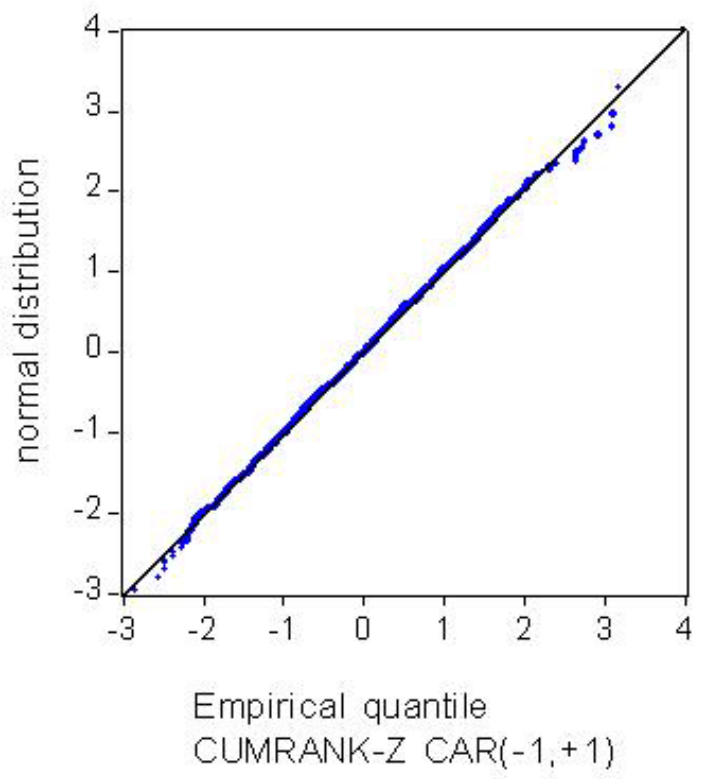

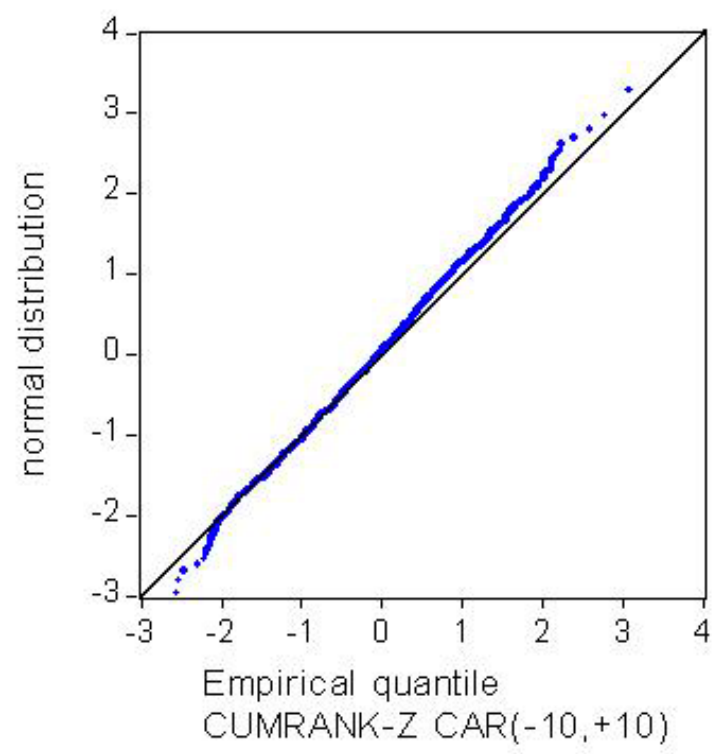

Figure 1: This figure illustrates the theoretical quantile-quantiles for the test statistic CUMRANK-Z in cases where the estimation period consists of 239 days and the event window consists of 21 days. The data is based on 1,000 simulations for portfolios of size $\mathrm{n}=50$ securities. The event day is denoted as $t=0$. The data consist of securities belonging to S\&P400-, S\&P500- and S\&P600-indexes from the period July, 1991 to October, 2009. The returns are calculated with the help of the market model presented in equation (51). 

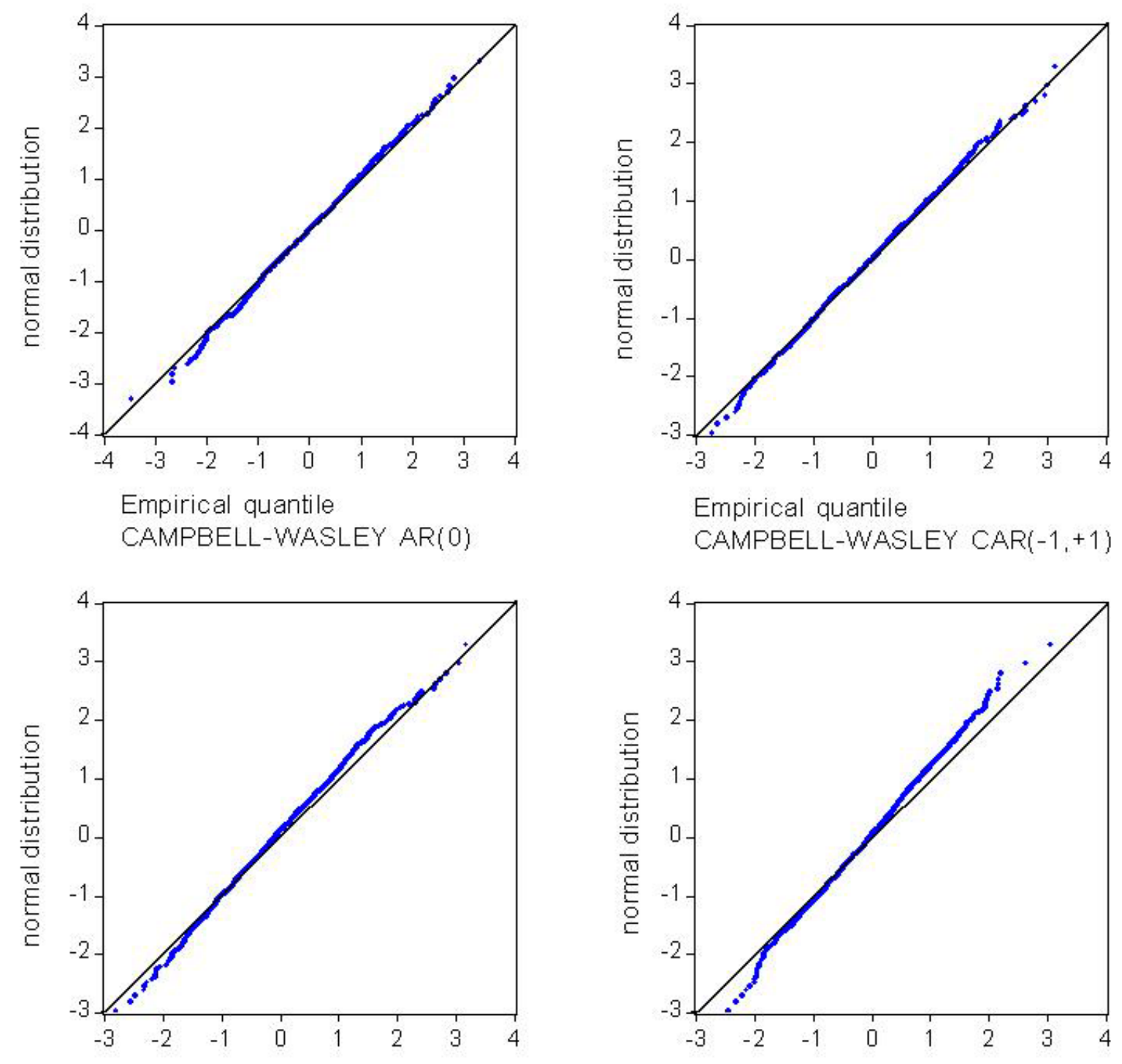

Empirical quantile

CAMPBELL-WASLEY CAR $(-5,+5)$

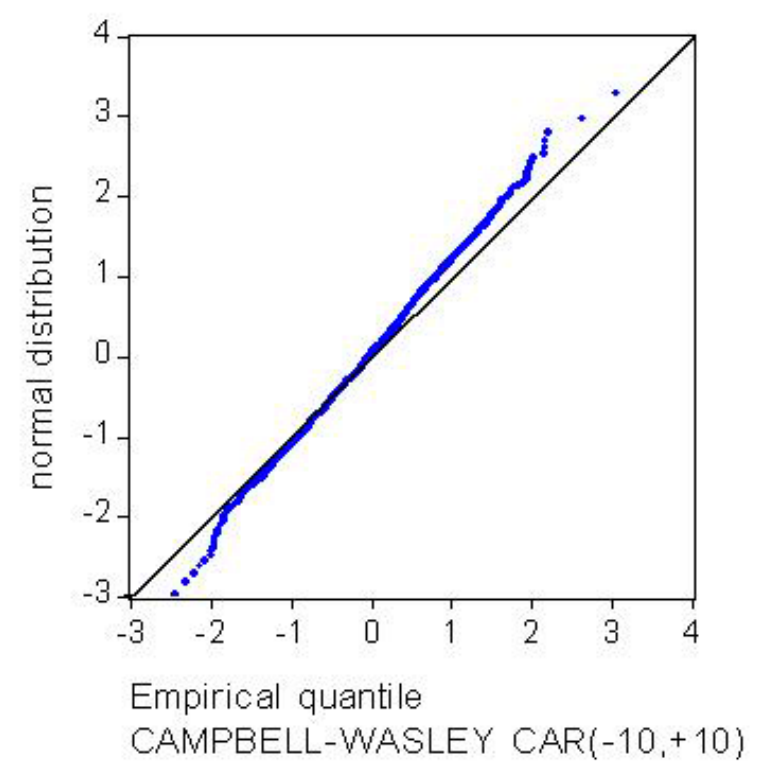

Figure 2: This figure illustrates the theoretical quantile-quantiles for the test statistic CAMPBELL-WASLEY in cases where the estimation period consists of 239 days and the event window consists of 21 days. General details of the simulation setup are given in the Figure 1. 

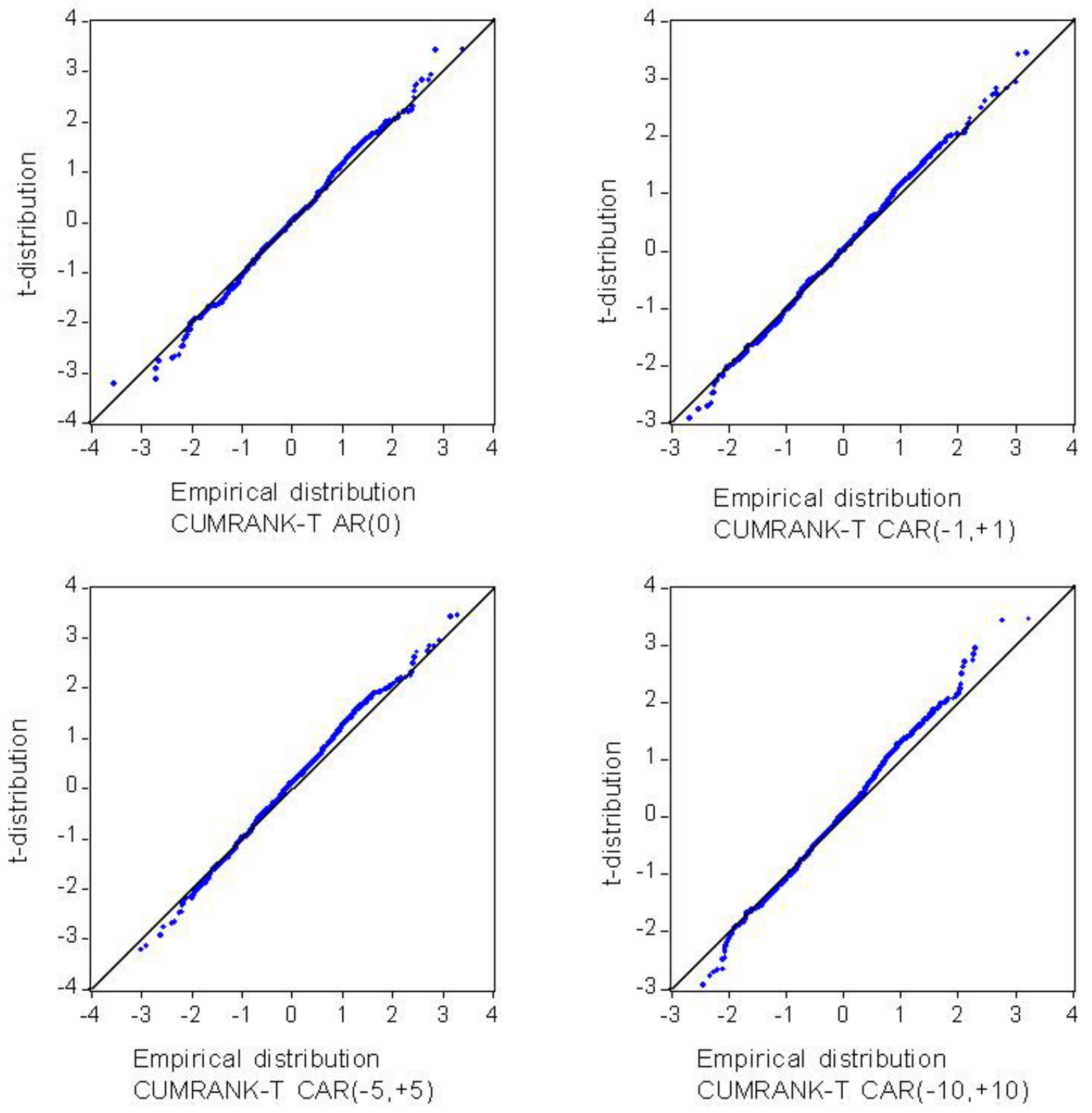

Figure 3: This figure illustrates the theoretical quantile-quantiles for the test statistic CUMRANK-T in cases where the estimation period consists of 239 days and the event window consists of 21 days. General details of the simulation setup are given in the Figure 1. 


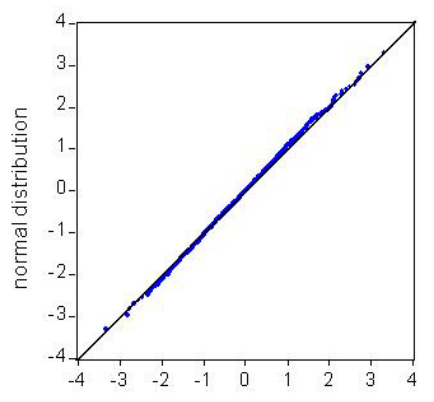

Empirical quantile

CAMPBELL-WASLEY AR(0)

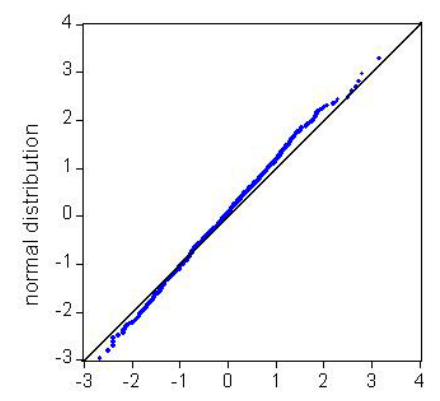

Empirical quantile

CAMPBELL-WASLEY CAR $(-5,+5)$
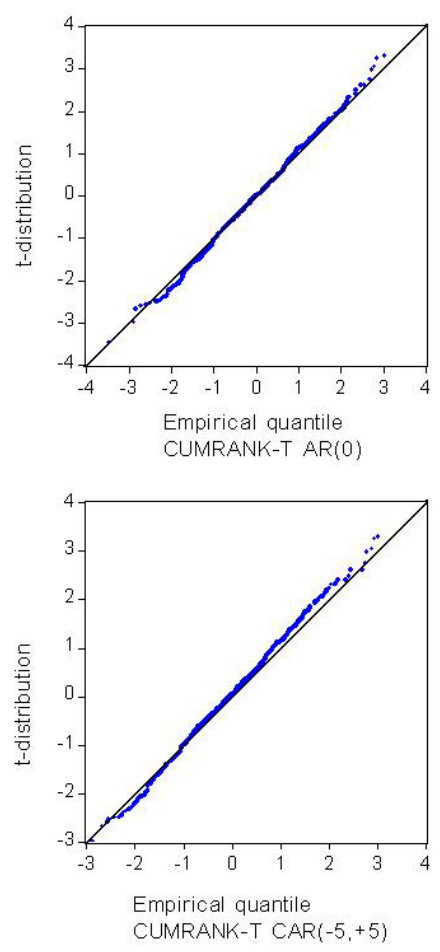

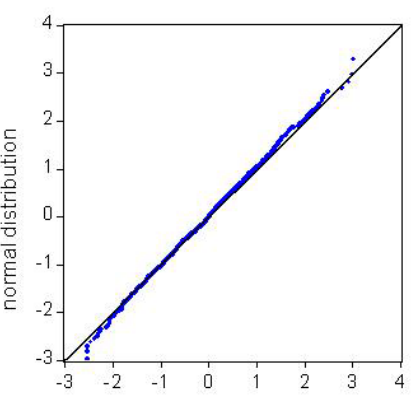

Empirical quantile

CAMPBELL-WASLEY CAR $(-1,+1)$

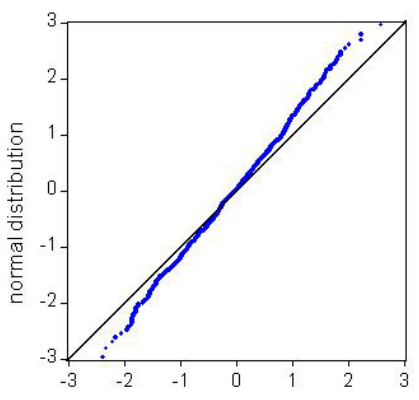

Empirical quantile

CAMPBELL-WASLEY CAR $(-10,+10)$
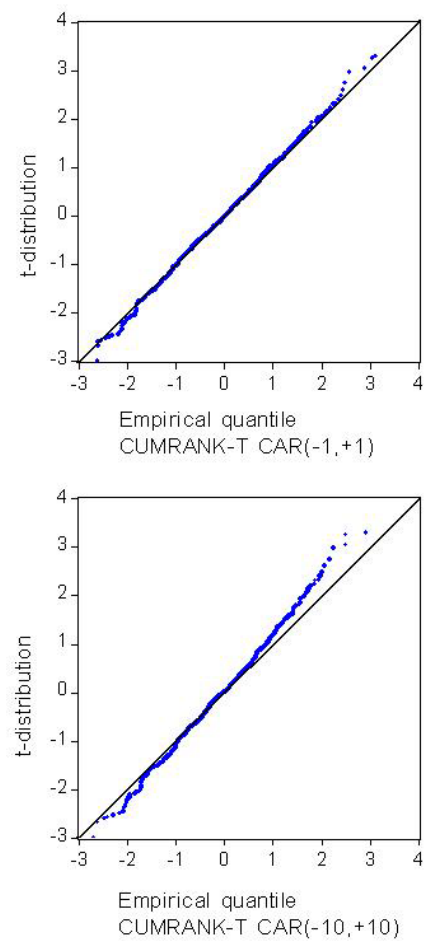

Figure 4: This figure illustrates the theoretical quantile-quantiles for the test statistics CAMPBELL-WASLEY and CUMRANK-T in cases where the estimation period consists of 100 days and the event window consists of 21 days. General details of the simulation setup are given in the Figure 1. 

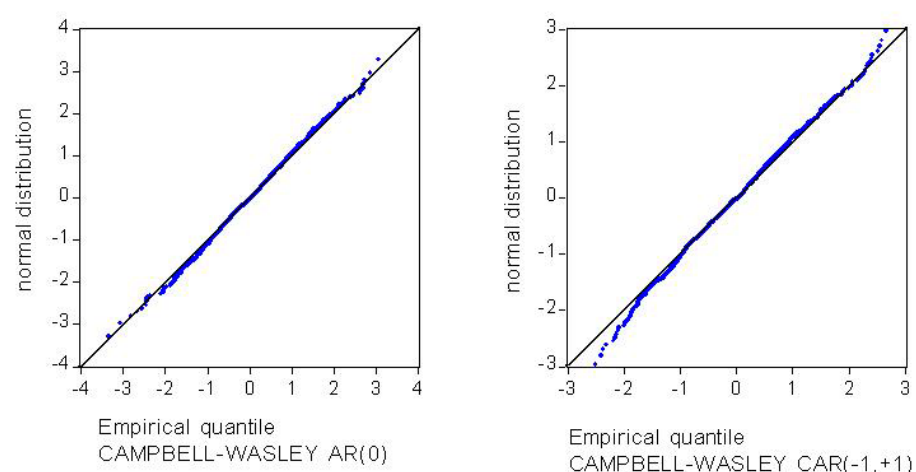

CAMPBELL-WASLEY AR(0)

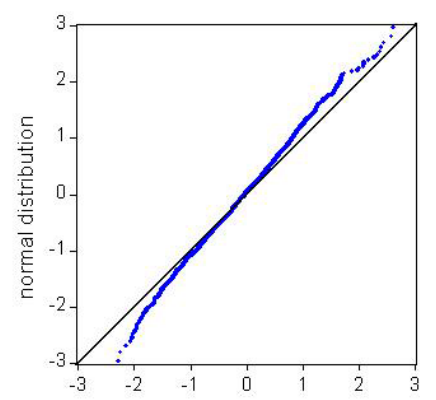

Empirical quantile

CAMPBELL-WASLEY CAR $(-5,+5)$

Empirical quantile

CAMPBELL-WASLEY CAR $(-1,+1)$

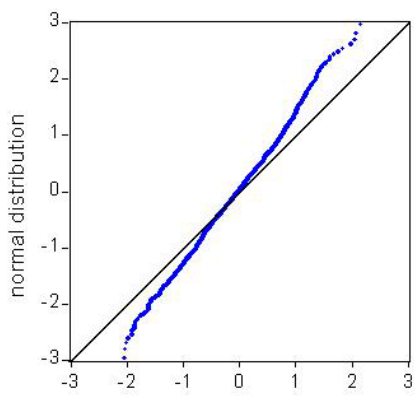

Empirical quantile

CAMPBELL-WASLEY CAR $(-10,+10)$
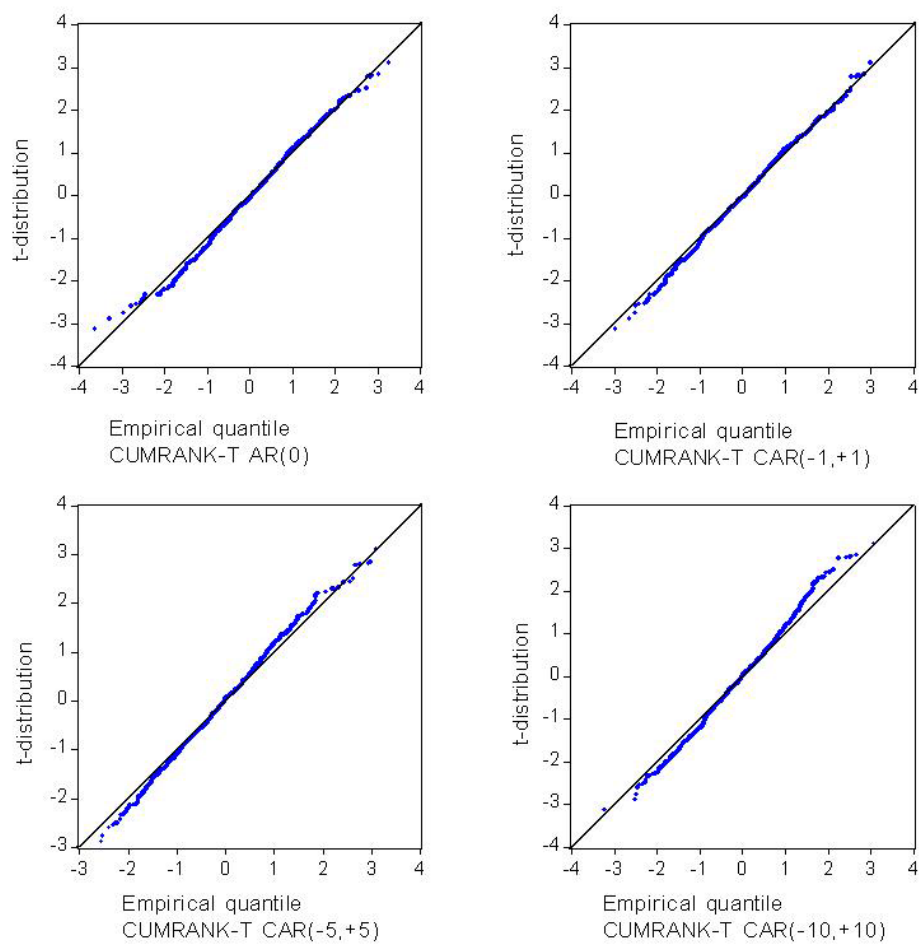

Figure 5: This figure illustrates the theoretical quantile-quantiles for the test statistics CAMPBELL-WASLEY and CUMRANK-T in cases where the estimation period consists of 50 days and the event window consists of 21 days. General details of the simulation setup are given in the Figure 1. 

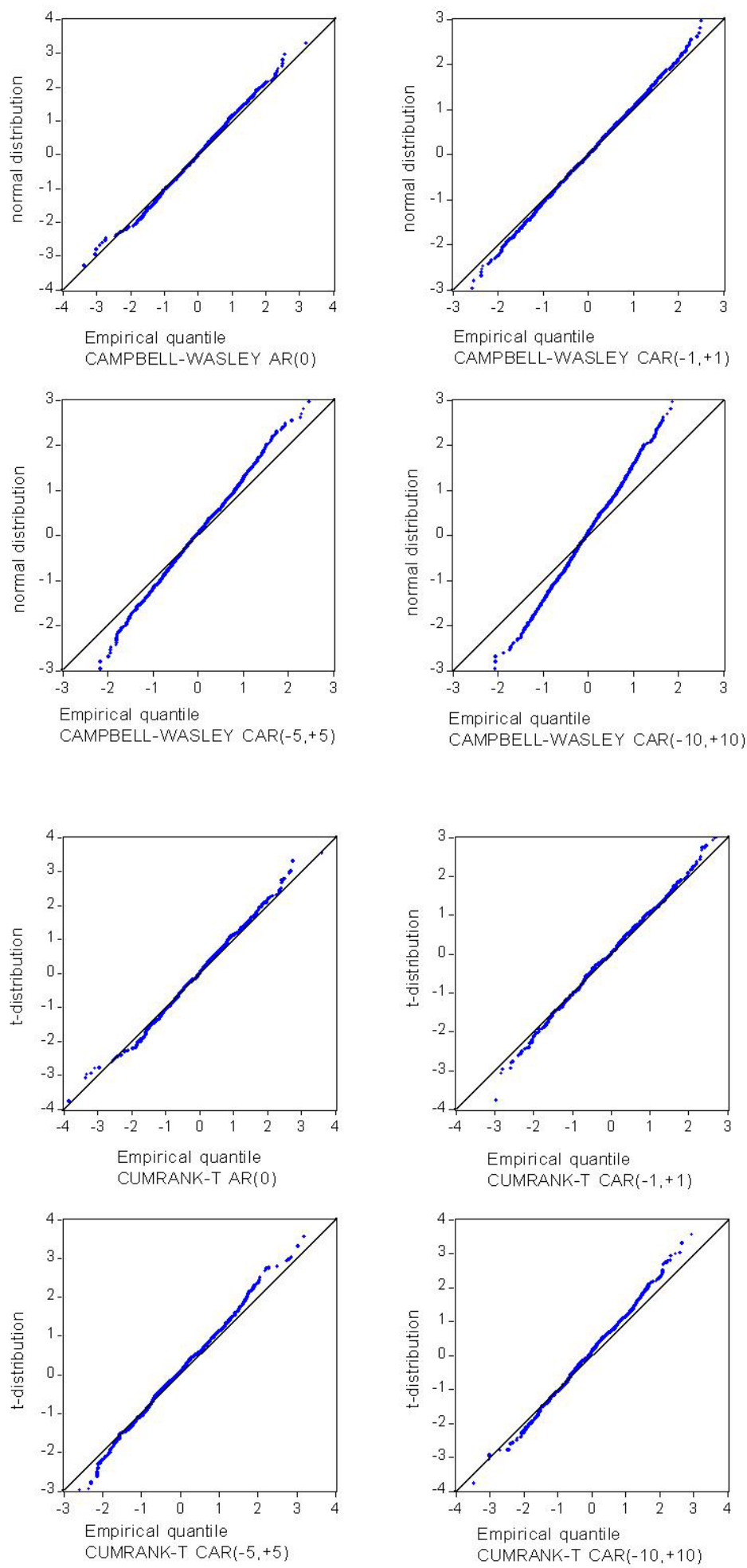

Figure 6: This figure illustrates the theoretical quantile-quantiles for the test statistics CAMPBELL-WASLEY and CUMRANK-T in cases where the estimation period consists of 25 days and the event window consists of 21 days. General details of the simulation setup are given in the Figure 1. 


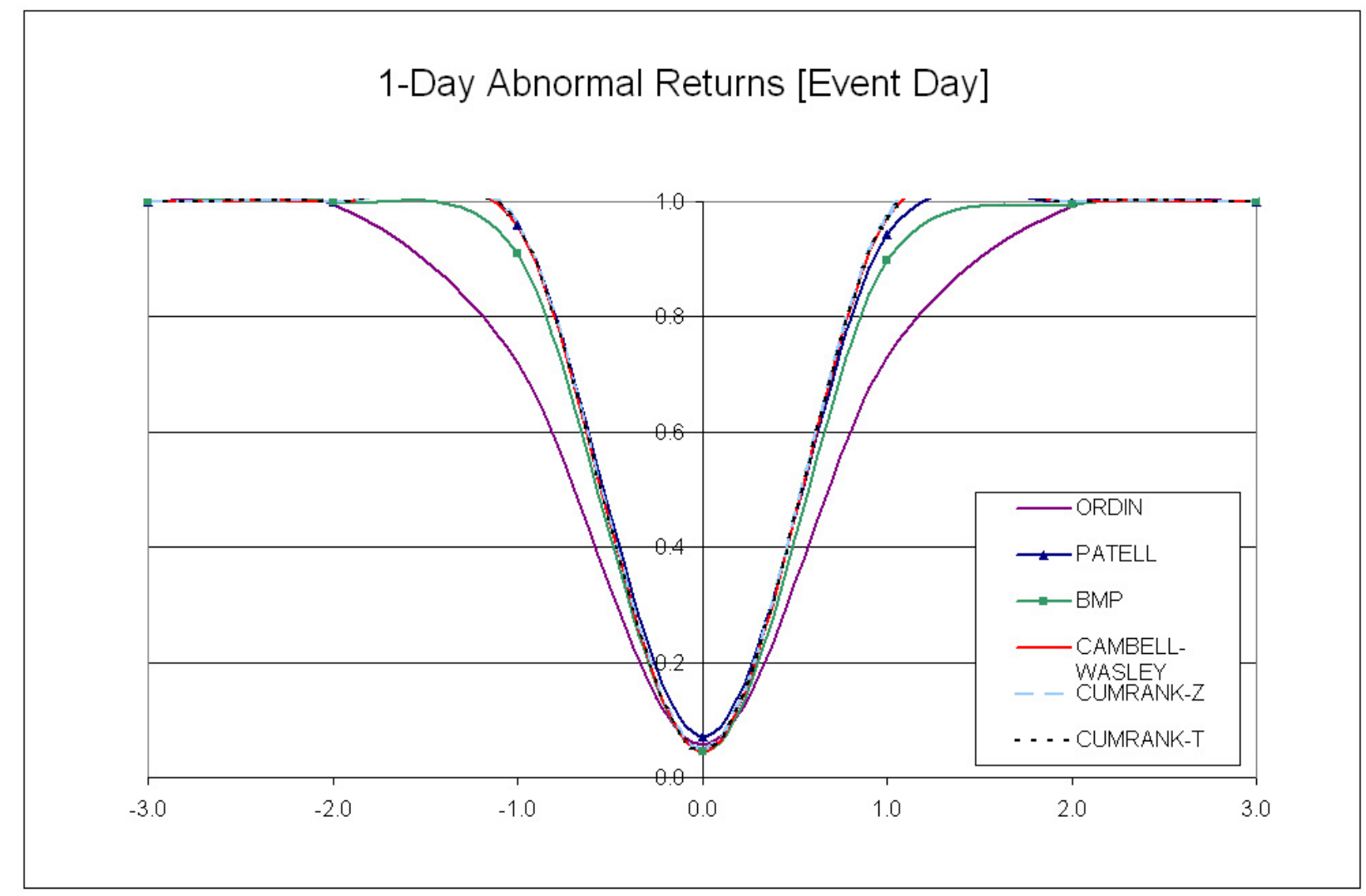

Figure 7: This Figure illustrates the power results of the test statistics ORDIN [Eq. (54)], PATELL [Eq. (56)], BMP [Eq. (57)], CUMRANK-Z [Eq. (32)], CAMPBELL-WASLEY [Eq. (36)] and CUMRANK-T [Eq. (42)] for two-tailed tests for testing single day abnormal returns $\mathrm{AR}(0)$ with an abnormal return ranging from -3 percent to +3 percent. The data is based on 1,000 simulations for portfolios of size $n=50$ securities with an estimation period of 239 days and event period of 21 days. The event day is denoted as $t=0$. The data consist of securities belonging to S\&P400-, S\&P500- and S\&P600-indexes from the period July, 1991 to October, 2009. The returns are calculated with the help of the market model presented in equation (51). 


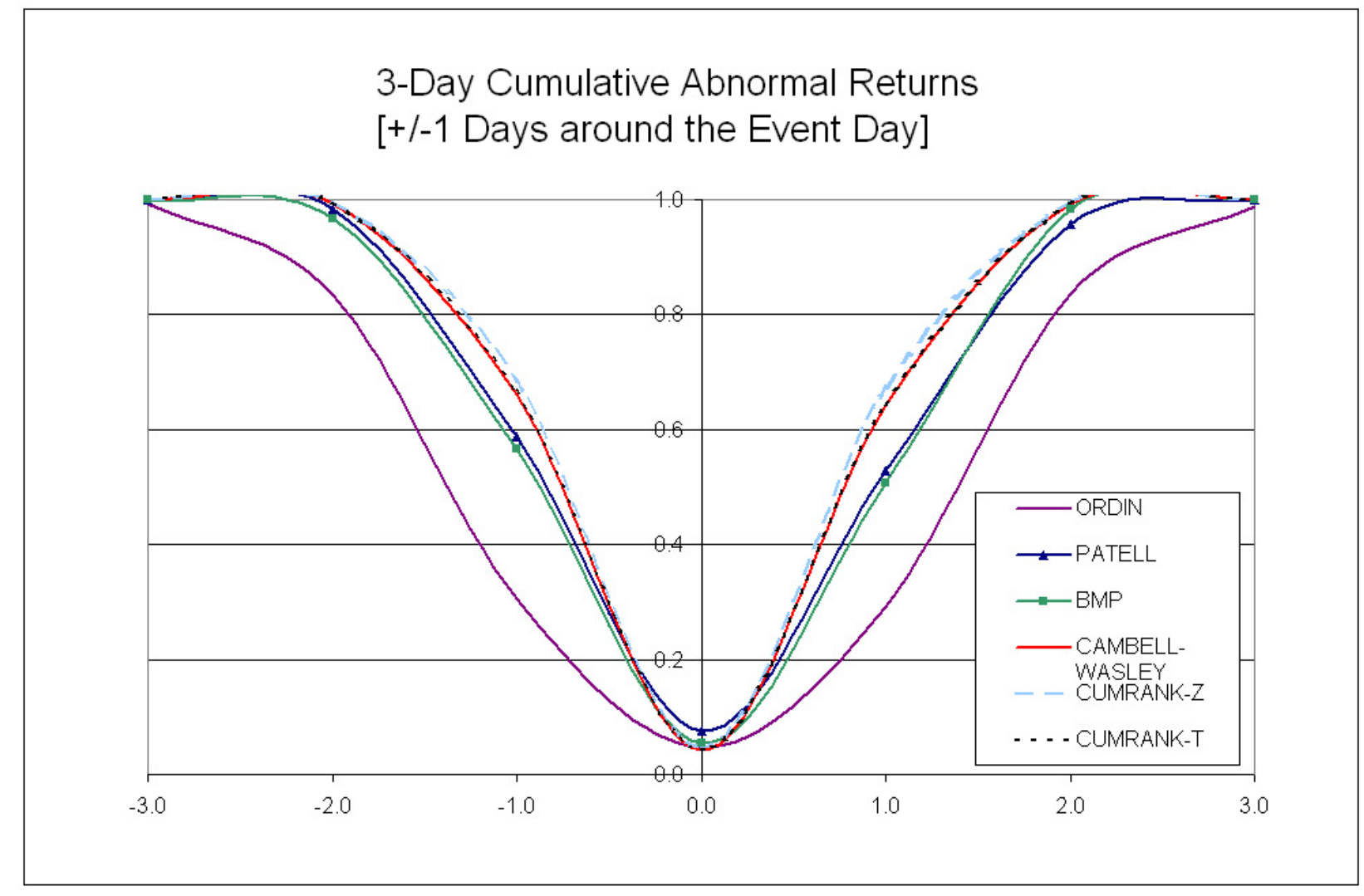

Figure 8: This Figure illustrates the power results of the test statistics ORDIN [Eq. (54)], PATELL [Eq. (56)], BMP [Eq. (57)], CUMRANK-Z [Eq. (32)], CAMPBELL-WASLEY [Eq. (36)] and CUMRANK-T [Eq. (42)] for two-tailed tests for testing cumulated abnormal returns $\operatorname{CAR}(-1,+1)$ with an abnormal return ranging from -3 percent to +3 percent. The abnormal return is divided by 3 and one 3rd of the abnormal return is added to each day's return within the 3 day window. General details of the simulation setup are given in the Figure 7. 


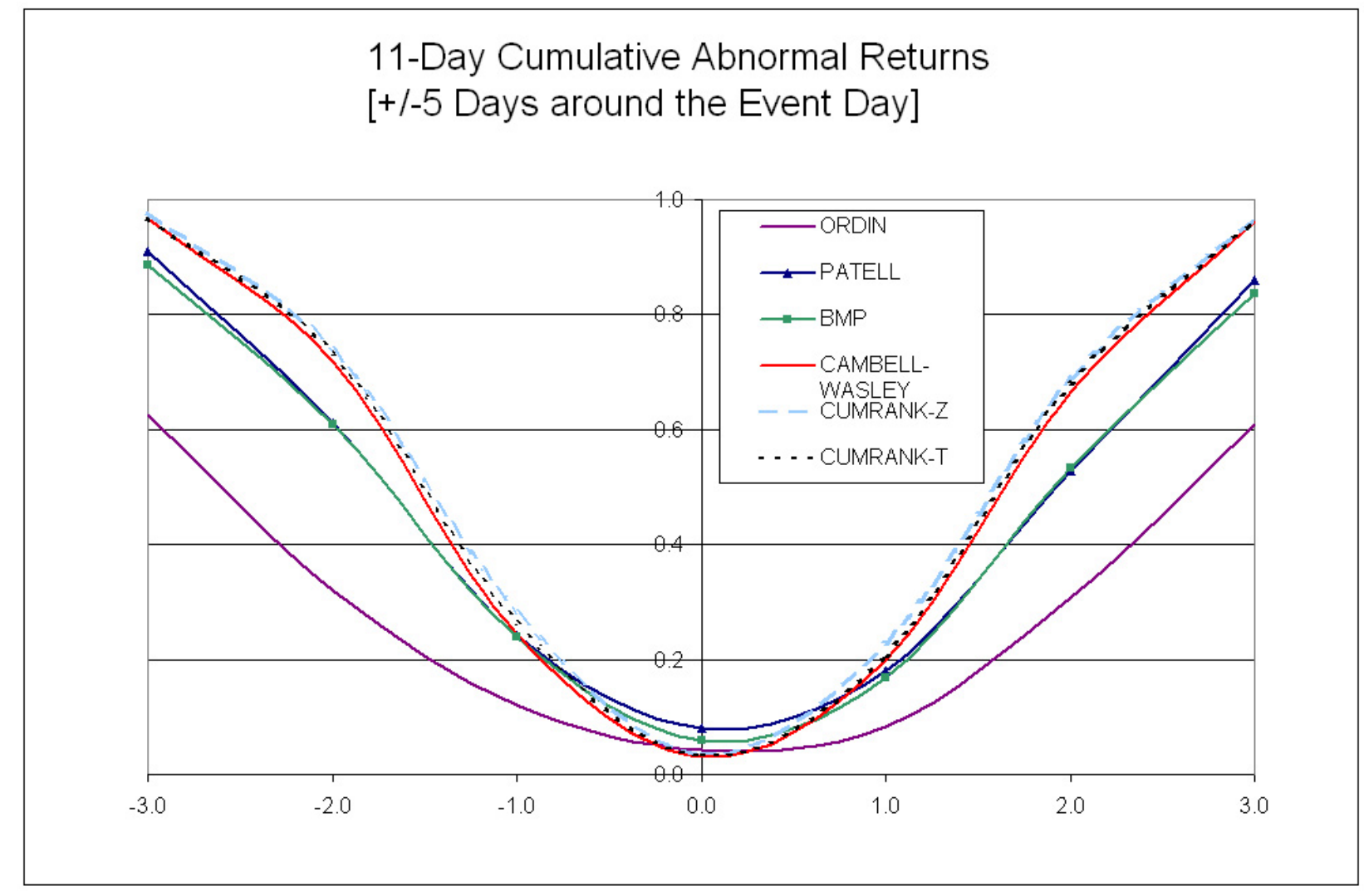

Figure 9: This Figure illustrates the power results of the test statistics ORDIN [Eq. (54)], PATELL [Eq. (56)], BMP [Eq. (57)], CUMRANK-Z [Eq. (32)], CAMPBELL-WASLEY [Eq. (36)] and CUMRANK-T [Eq. (42)] for two-tailed tests for testing cumulated abnormal returns $\operatorname{CAR}(-5,+5)$ with an abnormal return ranging from -3 percent to +3 percent. The abnormal return is divided by 11 and one 11th of the abnormal return is added to each day's return within the 11 day window. General details of the simulation setup are given in the Figure 7. 


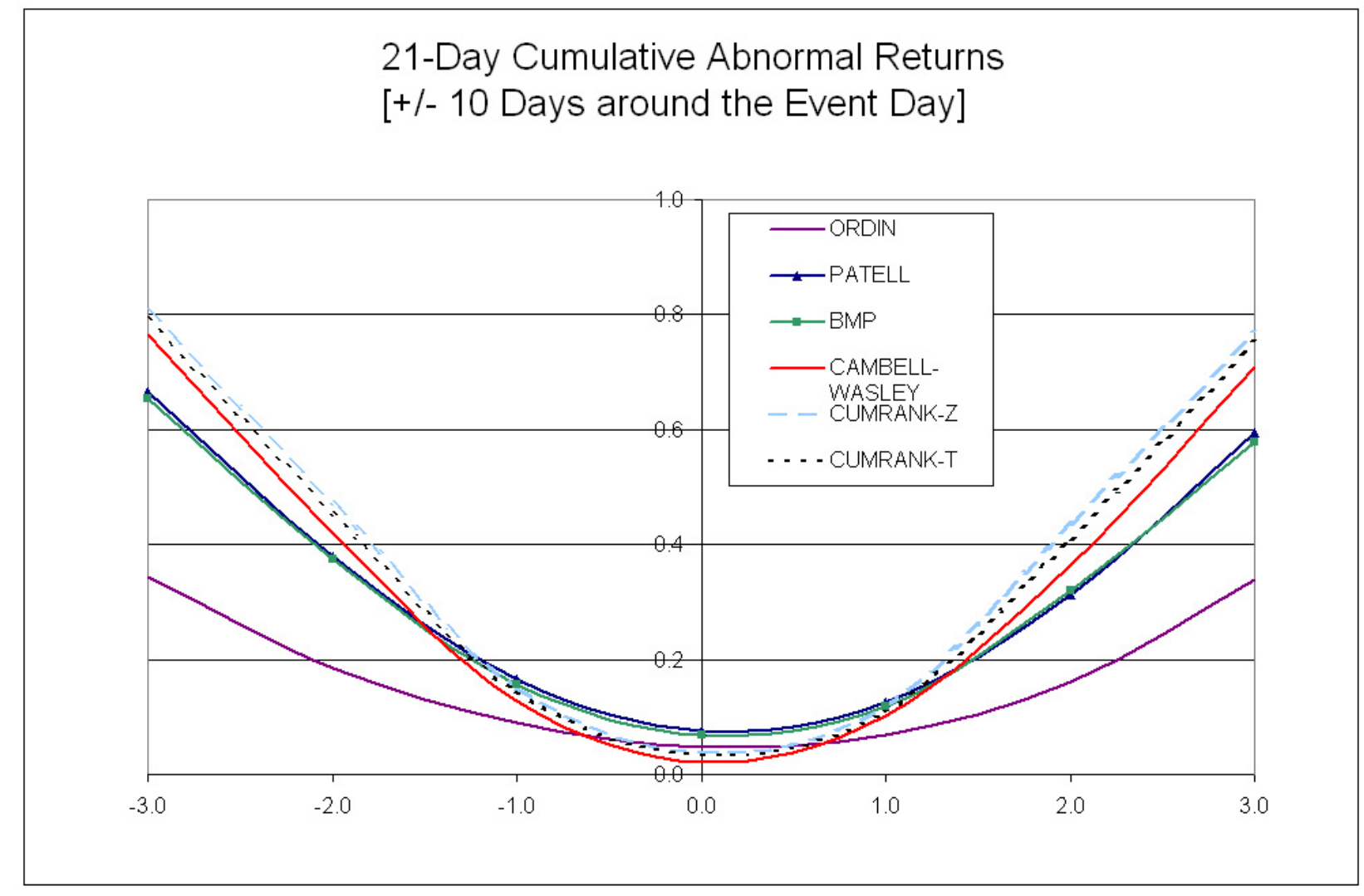

Figure 10: This Figure illustrates the power results of the test statistics ORDIN [Eq. (54)], PATELL [Eq. (56)], BMP [Eq. (57)], CUMRANK-Z [Eq. (32)], CAMPBELL-WASLEY [Eq. (36)] and CUMRANK-T [Eq. (42)] for two-tailed tests for testing cumulated abnormal returns $\operatorname{CAR}(-10,+10)$ with an abnormal return ranging from -3 percent to +3 percent. The abnormal return is divided by 21 and one 21st of the abnormal return is added to each day's return within the 21 day window. General details of the simulation setup are given in the Figure 7. 